\title{
Market Value Assessment and Idiosyncratic Tax-Price Risk: Understanding the Consequences of Alternative Definitions of the Property Tax Base
}

\author{
Nathan B. Anderson \\ January 9, 2012 \\ Department of Economics and \\ Institute of Government and Public Affairs \\ University of Illinois at Chicago \\ E-mail:nba@uic.edu
}

Acknowledgements: Thank you to the Minnesota Department of Revenue for providing data. Will Doerner, Therese McGuire, Andreas Pape, and two anonymous referees provided helpful comments. The Lincoln Institute of Land Policy provided financial assistance. 


\title{
Market Value Assessment and Idiosyncratic Tax-Price Risk: Understanding the Consequences of Alternative Definitions of the Property Tax Base
}

\begin{abstract}
I develop a framework, based on tax price, that measures the distributional consequences of any alternative property tax base definition. Using administrative data, I show that defining tax base as market value produces large amounts of idiosyncratic tax-price risk. I show that an assessment limit can reduce the tax-price risk generated by the market value definition and that the benefits of the assessment limit vary over time and accrue to a majority of taxpayers. In addition, I argue that the tax-price framework is appropriate for estimating behavioral responses to alternative tax base definitions.
\end{abstract}

\section{Introduction}

Around the world, the property tax is an important source of national and subnational government revenues and the scope of the tax is expanding with the recent introduction of new property taxes in China and Greece. ${ }^{1}$ In the United States, the property tax remains the largest independent source of local government revenues and as such provides local governments with the discretion over revenues and expenditures that forms the backbone of the U.S. fiscal federal system. ${ }^{2}$

In each country with property taxes, national and sometimes subnational governments create the core structure of the property tax system by making choices as to the definition of the property tax base. There is substantial variation across countries and within countries in how property tax systems define the tax base. For example, in Israel the tax base of the municipal property tax (the arnona) equals the size (in square meters) of a property while in most U.S. states the tax base is defined as a function of the estimated market value. In the U.S., there is important within-state over time variation in the tax base definition. For example, in 1978 Proposition 13 changed California's definition of property tax base from current market value to a definition based on the most recent sales price. Further, after Proposition 13, California now defines property tax base in some cases as the most recent sales price of a property and in other cases as the size (in square feet) of a property. ${ }^{3}$ Other states continue to introduce new exemptions and expand existing exemptions that alter property tax base definitions. Thus, although in the United States the legal basis for the

\footnotetext{
${ }^{1}$ Christian Science Monitor, January 28, 2011 and Financial Times Sept 12, 2011.

${ }^{2}$ In 2008, U.S. local (county, city, school district, special districts) governments raised $\$ 397$ billion in property taxes representing over $45 \%$ of general own source revenues. Property taxes have become an important source of revenue stability during the Great Recession. See Alm, Bushman, and Sjoquist (2011) and Lutz, Molloy, and Shan (2011).

${ }^{3}$ Mello-Roos districts in California often base property taxes on the size of the property and are explicitly barred from defining tax base as market value.
} 
property tax base is market value, in practice the wide array of exemptions means that no U.S. state defines the property tax base as current market value. Why do U.S. states choose to define the tax base of individual properties as something other than current market value?

This question is difficult to answer because research on the implications of the choice of tax base definition is limited. The lack of evidence on alternative choices of tax base definition also leaves countries introducing a new property tax, like China, without a theoretical framework or empirical evidence to guide them in an evaluation of the consequences of the choice of tax base definition. In this paper, I provide theoretical and empirical evidence on the distributional consequences of the choice of the definition of the property tax base.

There are many consequences of alternative tax base definitions; the single direct consequence is that, by redistributing a given level of total tax burden across taxpayers, an alternative tax base definition can, holding taxpayer behavior constant, change the current (static) and future (dynamic) distribution of the total tax burden across taxpayers. If the static and dynamic consequences of a switch to an alternative tax base definition are large enough then taxpayers change their behavior in an effort to avoid these consequences. The behavioral responses to the direct consequences of alternative tax base definitions affect the size of government (via tax prices and fiscal illusion), property values (via capitalization), mobility (via a "lock-in effect"), housing consumption (via the user cost of capital), and voter support for restrictions on government access to the tax base (via idiosyncratic tax-price risk). These behavioral consequences of alternative tax base definitions are indirect because they are caused by a behavioral response to the direct distributional consequences of an alternative tax base definition.

In this paper, I focus solely on the direct consequences of alternative definitions of property tax base, i.e., changes to the current and future distribution of the property tax burden that occur in the absence of behavioral responses. I develop and apply a new analytical framework for understanding and measuring the direct consequences of alternative tax base definitions for individual utility. My framework is based on a well-defined economic question: how much is an individual willing to pay to remain under the current tax base definition, thereby avoiding a switch to an alternative tax base definition. Importantly, because tax base definition affects future tax burdens it affects the expectations individuals have about their future tax payments. My framework allows me to demonstrate how alternative property tax base definitions affect the level, variance, and covariance of these expectations.

An important innovation in this paper is that I use tax price - defined for each property as its share of total tax base - as the basis of my analysis. In contrast, related prior work uses tax rates as its basis. Because tax prices depend only on the tax base definition (i.e., are revenue neutral) and tax rates depend on the revenue decisions of governments, using tax prices makes transparent the important distinction between decisions regarding the definition of tax base and decisions of 
governments to access that tax base to raise revenue.

This new framework is general in that it can be used to compare any two alternative tax base definitions. In my empirical work, I focus on comparing two specific alternative tax base definitions that feature prominently in current policy debates in the United States. The first tax base definition I consider is the current estimated market value of property. Defining the tax base in terms of estimated current market value is often considered the ideal definition of tax base because many believe that it is the most equitable and efficient. The second definition I consider is one that departs from current market value by placing a ceiling on the percentage increase in the taxable values of individual properties. This definition is often referred to as an assessment limit and, as of 2006, it existed in 20 U.S. states. ${ }^{4}$ Assessment limits are controversial because by departing from the market value definition they change the distribution of payments in ways thought inequitable, because payments are not based on market value, and inefficient, because they distort household mobility via a "lock-in" effect. In addition, assessment limits are thought to benefit a minority of taxpayers with large increases in property values at the expense of the vast majority of taxpayers with relatively smaller property value increases.

In the empirical work, I use a large, property-level administrative data set that allows me to measure the willingness to pay to remain under an assessment limit rather than switch to tax base defined as current estimated market value. One interesting result is that over the ten-year period the vast majority of properties experience some years in which they benefit (i.e., pay lower taxes) from the assessment limit and some years in which they lose (i.e., pay higher taxes). In fact, over the entire ten-year period the vast majority of properties are better off under the assessment limit than they would be under the definition of estimated market value. I demonstrate that the benefits of an assessment limit are not skewed towards the wealthy and that, although the average benefits of assessment limits are higher for properties with greater appreciation rates, the benefits are not focused exclusively on such properties.

Again, an important focus of this paper is how the definition of tax base affects the variance and covariance of expectations of future property tax payments. My central empirical result here is that an assessment limit benefits the vast majority of taxpayers by reducing the large amount of idiosyncratic tax-price variation generated under the market value definition. In addition, I show that the assessment limit makes the variance and covariance properties of future tax-price expectations relatively more attractive. To achieve these benefits, however, taxpayers must sacrifice the equity associated with being taxed at current market value. My results demonstrate these two alternative tax base definitions offer a tradeoff between achieving equity by taxing at market value and reducing the uncertainty of tax payments by limiting idiosyncratic tax-price variation.

Previous research estimating behavioral responses to alternative tax base definitions has relied

\footnotetext{
${ }^{4}$ See Anderson (2006b) for a list of states with assessment limits as of 2006.
} 
on measures of the direct consequences that have tax rates or exemption amounts as their basis. In this paper I demonstrate that my tax-price measure offers a different and arguably superior measure of direct consequences than tax-rate and exemption measures. Although this argument is not the focus of the current paper, that my tax-price measure is different and possibly superior to these other measures suggests that the tax-price measure of direct consequences has implications for research on behavioral responses to alternative tax base definitions like property tax capitalization, lock-in effects, and voter support for restrictions on local governments' fiscal autonomy. ${ }^{5}$ Thus, I hope that researchers conducting work on these indirect consequences of alternative tax base definitions consider using my tax-price measure as their measure of the direct consequences and, most importantly, I hope they state clearly the logic that underlies their measure of the direct consequence.

\section{Analytical Framework: Static}

In this section, I present the static framework for measuring the consequences of alternative definitions of the property tax base under the assumption of no behavioral responses. In this static analysis, I assume that the characteristics of properties that determine tax base under alternative definitions (e.g., market value, size) are fixed and do not change over time. If these characteristics are fixed over time then, under any tax base definition, the current distribution of the tax burden equals the future distribution. I relax this assumption in the dynamic analysis in Section 3.

Consistent with the assumption of no behavioral responses, in both the static and dynamic analysis I assume that switches in the definition of the property tax base do not affect the characteristics of the property (e.g., market value, size). This is a strong assumption and, in my view, necessary for clarity. My goal in this section is to provide a well-defined measure of the change in the distribution and level of property tax payments caused by a switch to an alternative tax base definition. It is this change in the level and distribution of property tax payments that, via behavioral responses, affects attributes of real estate like property values and the size of structures. My argument is that to understand correctly the behavioral responses to alternative definitions we must first define clearly what taxpayers are responding to, i.e., the changes in the level and distribution of property tax payments that occur in the absence of behavioral responses. I call the changes in the level and distribution of property tax payments that occur in the absence of behavioral responses the direct (first-order) consequences of alternative tax base definitions.

In measuring the direct consequences of an alternative tax base definition it is important to

\footnotetext{
${ }^{5}$ Examples of papers that rely on a measure of the consequences of alternative tax base definitions include Anderson (2006a), Anderson (2011), Bradley (2011), Cheung and Cunningham (2011), Dye, McGuire, and Merriman (2001), Ferreira (2010), Ihlanfeldt (2011), Rockoff (2010), and Skidmore, Ballard, and Hodge (2010).
} 
base the comparison on a well-defined and meaningful economic question. I ask how much is an individual willing to pay to remain under the current tax base definition, thereby avoiding a switch to an alternative tax base definition. To answer this question, I construct a measure, similar to measures of excess burden, based on a conceptual experiment where utility is held constant as tax base definition changes. ${ }^{6}$

A challenge in measuring the direct consequences of alternative tax base definitions is the difficulty in separating the effects of alternative tax base definitions on property tax payments from the effects of the levels of tax rates and tax revenues on property tax payments. In this paper, I develop a measure of the total effect and then separate this effect into two parts so as to measure only the effect of an alternative tax base definition and not the effects of tax rates and revenues. This measure is general and it can be used to compare any two alternative property tax base definitions.

For simplicity, assume all taxpayers consume public services financed exclusively by property taxes. The availability of additional sources of public service financing — sales taxes, income taxes, intergovernmental aid - does not affect the analysis. Private consumption for taxpayer $i$ equals permanent-income $\left(y_{i}\right)$ minus the property tax payment $\left(r_{i}^{j, R_{i}}\right)$ under tax base definition $j$ associated with the total revenue, $R_{i}$, raised by taxpayer $i$ 's jurisdiction. The public service equals the total amount of tax revenue collected by taxpayer $i$ 's jurisdiction $\left(R_{i}\right)$. Taxpayers have separable utility over private consumption and public services,

$$
U\left(y_{i}-r_{i}^{j, R_{i}}\right)+U\left(R_{i}\right)
$$

I use lower case letters to denote variables that vary across taxpayers and capital letters to denote variables that vary across jurisdictions but do not vary across taxpayers within the same jurisdiction. For example, property tax payments $\left(r_{i}^{j, R_{i}}\right)$ can vary across taxpayers within the same jurisdiction but tax revenue in the jurisdiction where taxpayer $i$ resides $\left(R_{i}\right)$ does not vary across taxpayers in that jurisdiction.

An individual's property tax payment is determined by the jurisdiction's chosen level of revenue and the definition of the tax base. Let the assessed (i.e., taxable) value of a taxpayer's property under tax base definition $j$ equal $a_{i}^{j}$. The assumption that each individual owns a property with fixed characteristics over time implies that assessed value is constant over time. Total assessed value (i.e., property tax base), $A_{i}^{j}$, equals the sum of the assessed values of all taxpayers in taxpayer $i$ 's jurisdiction. From accounting identities, the property tax payment $\left(r_{i}^{j, R_{i}}\right)$ of individual $i$

\footnotetext{
${ }^{6}$ Two examples of research that takes a similar approach to measuring the direct consequences of alternative tax base definitions are Dye and McMillen (2007) and O'Sullivan, Sexton, and Sheffrin (1995). In both cases, however, they do not separate the effects of alternative tax base definitions on property tax payments from the effects of the levels of tax rates and tax revenues on property tax payments and they do not consider what I call the dynamic implications.
} 
equals

$$
\begin{aligned}
r_{i}^{j, R_{i}} & \equiv p_{i}^{j} R_{i} \equiv \Gamma_{i}^{j, R_{i}} a_{i}^{j} \\
\text { where: } \quad p_{i}^{j} & \equiv \frac{a_{i}^{j}}{A_{i}^{j}} \text { and } \Gamma_{i}^{j, R_{i}} \equiv \frac{R_{i}}{A_{i}^{j}}
\end{aligned}
$$

For taxpayer $i$, the tax price of an additional dollar of property tax revenue equals $p_{i}^{j}$. This can also be called the tax share because it equals the share of total property taxes paid by taxpayer $i$. The statutory property tax rate, $\Gamma_{i}^{j, R_{i}}$, is the rate that raises revenue equal to $R_{i}$. The tax base definition and the revenue level determine the magnitude of the statutory tax rate. For example, defining tax base as the area (in square meters) of a property requires a different tax rate than the tax rate required to raise the same revenue defining tax base as the estimated market value.

I ask how much a taxpayer is willing to pay, holding public services constant, to remain under the current tax base definition $(j=0)$, thereby avoiding a switch to an alternative tax base definition $(j=1)$. The answer to this question is the willingness to pay to remain under the current tax base definition and measures the total direct effect of a switch to an alternative tax base definition. The willingness to pay $\left(z_{i}\right)$ to remain under definition $j=0$ is defined in the relation to a conceptual experiment that holds utility constant between the two alternative definitions:

$$
\begin{array}{r}
\left.U\left(y_{i}-r_{i}^{0, R_{i}}-z_{i}\right)+U\left(R_{i}\right)=U\left(y_{i}-r_{i}^{1, R_{i}}\right)\right)+U\left(R_{i}\right) \\
z_{i}=r_{i}^{1, R_{i}}-r_{i}^{0, R_{i}}=R_{i}\left[p_{i}^{1}-p_{i}^{0}\right]
\end{array}
$$

Equation (5) demonstrates that, for a taxpayer $i$, the total direct effect of a switch to an alternative tax base definition equals the revenue-neutral change in the property tax payment. Note that maintaining the same $R_{i}$ across tax base definitions is critical to the definition of $z_{i}$ as willingness to pay. If $R_{i}$ were not constant then to remain indifferent between the two definitions the taxpayer has to be compensated for both the change in the tax payment (i.e., private consumption) and the change in public services. ${ }^{7}$ For taxpayers $i$ and $k$ the difference in willingness to pay equals

$$
z_{i}-z_{k}=R_{i}\left[\left(p_{i}^{1}-p_{i}^{0}\right)\right]-R_{k}\left[\left(p_{k}^{1}-p_{k}^{0}\right)\right]
$$

which depends on both the revenue levels in each taxpayer's jurisdiction and across-taxpayer differences in the effects of an alternative tax base definition on tax price.

The switch to an alternative tax base definition affects tax prices. Then these tax price effects are multiplied by the revenue level to determine the total direct effect of the switch. To measure

\footnotetext{
${ }^{7}$ This derivation is, of course, dependent on the exact question being asked and is related to the concepts of equivalent and compensating variation as well as measures of excess burden. See Auerbach and Hines (2002).
} 
only the direct consequences of alternative tax base definitions it is necessary to isolate the acrosstaxpayer variation in $z_{i}$ caused by tax prices and not by tax revenues. Revenues vary across jurisdictions for many reasons (e.g., preferences, alternative revenue sources, wealth); across-definition tax-price differences vary across taxpayers only because of across-taxpayer differences in the effects of alternative tax base definitions on tax price.

To measure only the direct consequences of alternative tax base definitions, and not the effects of tax rates and tax revenues, I divide both sides of equation (5) by $R_{i}$ to generate an expression of willingness to pay per-dollar of tax revenue,

$$
\frac{z_{i}}{R_{i}}=\left[p_{i}^{1}-p_{i}^{0}\right]
$$

i.e., the difference in the tax price of taxpayer $i$ between definition $j=1$ and $j=0$. The difference in willingness to pay per dollar of tax revenue between taxpayer $i$ and taxpayer $k$ equals

$$
\frac{z_{i}}{R_{i}}-\frac{z_{k}}{R_{k}}=\left(p_{i}^{1}-p_{i}^{0}\right)-\left(p_{k}^{1}-p_{k}^{0}\right)
$$

Because this difference depends only on tax prices a comparison of the $\frac{z_{i}}{R_{i}}$ of taxpayers in different jurisdictions (or in the same jurisdiction) measures only the relative benefits of alternative tax base definitions. If $\frac{z_{i}}{R_{i}}>\frac{z_{k}}{R_{k}}>0$ then taxpayer $i$ benefits more from the current tax base definition than taxpayer $k$ and if $\frac{z_{i}}{R_{i}}<0$ then taxpayer $i$ loses from the current tax base definition relative to the alternative. Also note, that because $R_{i}$ does not vary across taxpayers within a jurisdiction, a within-jurisdiction ranking of taxpayers in terms of $\frac{z_{i}}{R_{i}}$ is equivalent to a within-jurisdiction ranking in terms of $z_{i}$.

\section{Analytical Framework: Dynamic}

In the dynamic framework, I consider how the definition of tax base can affect how individuals expect their tax prices to behave over time. I assume that although characteristics of properties change over time that the choice of tax base definition has no effect on these changes. That is, as in the static framework, I do not allow for behavioral responses to the tax base definition.

Under any tax base definition, changes in the tax price of an individual taxpayer are caused only by relative, rather than absolute, changes in the assessed values of the property. For example, if the size (value) of a taxpayer's property increases by five percent and the total size (value) of all properties increases by five percent then the taxpayer's tax price does not change. If relative changes do occur - i.e., there is within-jurisdiction heterogeneity in changes in assessed value then tax prices change. 
That tax prices may change implies that it may be important to measure willingness to pay $\left(\frac{z_{i}}{R_{i}}\right)$ at more than one point in time. For example, the evolution of tax prices over time may imply that a taxpayer with a positive willingness to pay in one period has a negative willingness to pay in a future period. This is an empirical question and calculating willingness to pay at more than one point in time is a straightforward empirical exercise. If I measure $\frac{z_{i}}{R_{i}}$ at different points in time and willingness to pay shows little variation then we conclude that measuring at one point in time renders an accurate description of the consequences of alternative tax base definitions.

That tax prices may change over time also implies that taxpayers may have some uncertainty around their expectations of future tax prices. I want to emphasize that uncertainty about future tax prices does not require entirely unpredictable future assessed values. For example, if assessed value is defined as current market value, a homeowner might have information about future home improvements or future changes in local amenities that will affect his future assessed value. Thus, his future assessed value is somewhat predictable. It is difficult to argue, however, that such information gives him the ability to perfectly predict his future home value. Moreover, to perfectly predict his future tax price, the homeowner must perfectly predict how his home value appreciates relative to other properties in his jurisdiction.

I now present a simple framework that describes the consequences of alternative tax base definitions for expected utility under the assumption that future tax prices are somewhat unpredictable. If future tax prices are somewhat unpredictable then there is tax-price risk. To consider how taxprice risk affects taxpayer utility I use the quadratic utility function. I use the quadratic utility function because it provides a simple framework for considering the effects of risk on expected utility. The quadratic utility function allows me to express expected utility as a function of the mean, variance, and covariance of tax price. A taxpayer's expected utility at time $t$ equals

$$
E[U]=E\left[U\left(c_{i, t}, R_{i, t}\right)\right]=E\left[U\left(y_{i, t}-r_{i, t}^{j, R_{i}}\right)\right]+\phi E\left[U\left(R_{i, t}\right)\right]
$$

where

$$
U(c)=c-\frac{\phi}{2} c^{2} \quad \text { and } \quad U^{\prime}(c)=1-\phi>0
$$

To focus only on the direct consequences of the tax base definition, I assume future $R$ is known with certainty and does not vary across tax base definitions. Future tax prices equal

$$
p_{i, t}^{j}=\mu_{i, t}^{j}+\epsilon_{i, t}^{j}
$$

where $\mu_{i, t}^{j}$ is the expected future tax price of individual $i$ and $\epsilon_{i, t}^{j}$ is a mean-zero random variable. 
If there is uncertainty about future tax price then $V A R\left(\epsilon_{i, t}^{j}\right)>0$. Future permanent income equals

$$
y_{i, t}=\omega_{i, t}+\theta_{i, t}
$$

where $\omega_{i, t}$ is the expected future permanent income of individual $i, \theta_{i, t}$ is a mean-zero random variable, and if there is uncertainty about future permanent income then $V A R\left(\theta_{i, t}\right)>0$. The lack of a $j$ superscript on the income variables implies that the tax base definition does not have a direct effect on permanent income.

Given these assumptions and dropping the $t$ subscripts, the expected utility of future consumption equals

$$
E\left[U\left(c_{i}\right)\right]=\omega_{i}-\mu_{i}^{j} R_{i}-\frac{\phi}{2}\left[\omega_{i}-\mu_{i}^{j} R_{i}\right]^{2}-\frac{\phi}{2}\left[V A R\left(\theta_{i}\right)+R_{i}^{2} V A R\left(\epsilon_{i}^{j}\right)-2 R_{i} \operatorname{COV}\left(\theta_{i}, \epsilon_{i}^{j}\right)\right]
$$

Given a value for $\phi$, I can calculate the expected utility of taxpayer $i$ under any tax base definition. The magnitude and sign of the difference in expected utility between any two tax base definitions depends on the assumption of quadratic utility and, given that assumption, on the unobservable parameter $\phi$. Although it seems a mistake to take equation (13) literally and calculate this difference, the equation does provide some basic guidance as to how tax base definitions affect expected utility.

In this simple model with no behavioral responses, tax base definitions affect expected utility only via their effects on the mean, variance, and covariance of tax price. Thus, to understand the effects of alternative definitions on expected utility it is necessary to measure the effects of alternative tax base definitions on mean, variance, and covariance of tax price. To do this, consider the following three regressions that produce estimates of three $\delta_{x}^{j}$ coefficients

$$
\begin{aligned}
\mu_{i}^{j} & =\gamma_{\mu}+\delta_{\mu}^{j} \cdot 1\{(j=1)\}+u_{i} \\
V A R\left(\epsilon_{i}^{j}\right) & =\gamma_{v}+\delta_{v}^{j} \cdot 1\{(j=1)\}+\xi_{i} \\
\operatorname{COV}\left(\theta_{i}, \epsilon_{i}^{j}\right) & =\gamma_{c}+\delta_{c}^{j} \cdot 1\{(j=1)\}+v_{i}
\end{aligned}
$$

These regressions estimate between-definition differences in the average of the dependent variable and we can compare alternative tax base definitions by estimating these $\delta_{x}^{j}$ coefficients for the mean, variance, and covariance of tax price. In each of these regressions, each property has two observations for the dependent variable: one with tax base definition zero and the other with tax base definition one. The independent variable $-1\{(j=1)\}-$ is the same in all three equations and equals one when the tax base definition is $j$ and zero when it is not. The $\gamma$ coefficients are constants and the estimated $\delta_{x}^{j}$ coefficients reflect the "average treatment effect" of switching to an 
alternative tax base definition on the mean, variance, and covariance of tax price. $^{8}$

Estimates of the $\delta_{x}^{j}$ coefficients can help determine whether an alternative tax base definition increases expected utility. To see this, note that a simple reduced-form equation that expresses the effects of tax base definition on expected utility $(E U)$ is

$$
\begin{aligned}
E U_{i}^{j}= & \alpha_{0}+\alpha_{1}\left(\mu_{i}^{0}+\delta_{\mu}^{j} \cdot 1\{(j=1)\}\right)+\alpha_{2}\left(V A R\left(\epsilon_{i}^{0}\right)+\delta_{v}^{j} \cdot 1\{(j=1)\}\right) \\
& +\alpha_{3}\left(\operatorname{COV}\left(\theta_{i}, \epsilon_{i}^{0}\right)+\delta_{c}^{j} \cdot 1\{(j=1)\}\right)
\end{aligned}
$$

Equation $13 \Longrightarrow \alpha_{1}<0, \alpha_{2}<0$, and $\alpha_{3}>0$

where $\delta_{x}^{j}$, defined as above, equals the change in $x$ - mean, variance, or covariance - caused by a switch from tax base definition 0 to tax base definition $1 .{ }^{9}$ We know from equation (13) that $\alpha_{1}<0, \alpha_{2}<0$, and $\alpha_{3}>0$. Because $\alpha_{1}<0$, if expected tax price $\left(\mu^{j}\right)$ increases then expected utility decreases. The intuition is that, all else equal, a person is made better off by a lower price. Because $\alpha_{2}<0$, if the variance of the unexpected component of future tax prices rises then expected utility falls. The intuition is that when a consumer cannot adjust his or her own consumption of a good, in this case (by assumption) $R$, then a mean-preserving spread in the expected price of the good reduces expected utility. Finally, because $\alpha_{3}>0$, if the covariance between the unexpected component of future permanent income and the unexpected component of future tax price rises then expected utility increases. The intuition is hedging between the tax payment and income; if the unexpected components of tax payment and income are positively correlated then consumption is less volatile than it is when they are negatively correlated. ${ }^{10}$

Knowing the signs of the $\alpha$ coefficients implies that estimates of the $\delta_{x}^{j}$ coefficients - the average treatment effects for the mean, variance, and covariance - can help determine whether an alternative tax base definition increases expected utility. In some cases, the signs of the $\delta_{x}^{j}$ coefficients are sufficient to sign the effect on expected utility. For example, if $\delta_{\mu}^{1}$ is positive, $\delta_{v}^{1}$ is positive, and $\delta_{c}^{1}$ negative, then we know that tax base definition one reduces expected utility relative to tax base definition zero. In other cases the signs of the $\delta_{x}^{j}$ coefficients are not sufficient to determine the direction of the effect on expected utility. In these cases, however, the signs of the $\delta_{x}^{j}$ coefficients inform as to the mechanisms through which an alternative tax base definition increases expected utility. For example, if $\delta_{\mu}^{1}<0$ then we know that tax base definition one does not increase expected utility by reducing expected tax price. The magnitudes of the $\delta_{x}^{j}$ coefficients also allow us to make inferences about these mechanisms. If $\delta_{c}^{1}$ is arguably small then it seems

\footnotetext{
${ }^{8}$ To isolate the effect of the alternative tax base definition on the variance one can control for the mean in the variance regression so that changes in the variance reflect only mean-preserving spreads.

${ }^{9}$ This equation ignores that in equation (13) expected utility is a quadratic function of the expected tax price and that the magnitude of the $\alpha$ coefficients depend on tax revenue and permanent income.

${ }^{10}$ See, for example, Varian (1980).
} 
that, in terms of covariance, tax base definition one cannot provide a meaningful advantage relative to tax base definition zero.

Alternative tax base definitions also have direct consequences for the share of tax price variation within a jurisdiction that is common (i.e., shared) rather than idiosyncratic. The share of variation in tax prices that is common versus idiosyncratic is important because it can have indirect consequences expected utility and collective decision-making. For example, Anderson and Pape (2011) show that, under rational expectations, unpredictable idiosyncratic tax-price variation reduces expected utility more than unpredictable common tax-price variation.

As I show below, tax price can be expressed as the product of a common component and an idiosyncratic component. Let the term $A_{i, g, t}^{j}$ denote the total assessed value, under definition $j$, of a proper subset $(g)$ of all taxpayers in the same jurisdiction as taxpayer $i$. For example, $g$ could be the subset of all taxpayers that own residential property and taxpayers not in group $g$ are owners of non-residential property. With this new notation, I rewrite the expression for tax price as

$$
\begin{gathered}
p_{i, t}^{j} \equiv s_{i, t}^{j} S_{i, t}^{j} \equiv \frac{a_{i, t}^{j}}{A_{i, t}^{j}} \\
\text { where } s_{i, t}=\frac{a_{i, g, t}^{j}}{A_{i, g, t}^{j}} \quad S_{i, t}=\frac{A_{i, g, t}^{j}}{A_{i, t}^{j}} \\
A_{i, g, t}^{j}=\sum_{i \in g} a_{i, g, t}^{j} \quad \text { and } A_{i, g, t}^{j}<A_{i, t}^{j}
\end{gathered}
$$

If tax prices changes are due to changes in $S_{i, t}^{j}$, then all taxpayers in $g$ experience a common change in their tax prices. If tax price changes are instead due to changes in $s_{i, t}^{j}$ then tax price changes are not all common within the group $g$ because, by definition, within subset $g$ these changes cannot all be of the same direction and magnitude. ${ }^{11}$

If there is tax-price risk in both components of tax price then expressing future tax prices in natural logs separates the common and idiosyncratic components

$$
\ln \left(p_{i, t}^{j}\right)=\ln \left(\bar{s}_{i, t}^{j}+\psi_{i}^{j}\right)+\ln \left(\bar{S}_{i, t}^{j}+\Psi_{i}^{j}\right)
$$

where, $\bar{s}$ and $\bar{S}$ are tax price expectations and $V A R\left(\psi_{i}^{j}\right)>0$ and $V A R\left(\Psi_{i}^{j}\right)>0$ represent uncertainty in $s$ and $S$. Within a jurisdiction, the variance in $\Psi_{i}^{j}$ is shared by all taxpayers in $g$ and the variance in $\psi_{i}^{j}$ is not shared across all taxpayers in $g$ and may be idiosyncratic to taxpayer $i$.

In sum, if tax prices change over time then willingness to pay may change over time and future

\footnotetext{
${ }^{11}$ Note that $p_{i, t}^{j}=s_{i, t}^{j} S_{i, t}^{j}$ defines the price of all taxpayers in the same jurisdiction as taxpayer $i$, i.e., not only the taxpayers in the proper subset $g$. Also note that, by definition, the sum of the $s_{i, t}^{j}$ for all $i \in g$ equals one.
} 
tax prices may be somewhat unpredictable. Understanding the consequences of alternative tax base definitions for unpredictable tax prices and expected utility requires a focus on the mean, variance, and covariance of tax price as well as the share of tax-price variation that is common.

\section{Data Description and Alternative Tax Base Definitions}

In this section, I describe how I apply my framework to a unique administrative data set to measure the direct consequences of two broad classes of alternative tax base definitions. The first alternative tax base definition equals estimated current market value. Under this definition assessed values are updated each year to reflect any changes in the estimated market value of the property. The second alternative tax base definition equals estimated current market value minus an exemption administered via an assessment limit on residential property. Under this definition, the assessed value of non-residential property equals current market value and the assessed value of residential property equals estimated market value minus an exemption. The exemption can vary across residential properties at one time and within a residential property over time and is designed to prevent the assessed value of an individual residential property from increasing by more than a specified maximum percentage from one year to the next. I want to emphasize again, however, that the framework above can be used to compare any two tax base definitions and that what follows is just one application of this framework.

\subsection{Data and Measurement}

First, I discuss measurement of the static consequences of alternative tax base definitions. To produce the static measure $\left(\frac{z_{i}}{R_{i}}\right)$ of willingness to pay for individual taxpayers at different points in time requires a taxpayer-level panel data set that allows for the construction of tax prices under alternative tax base definitions. The construction of the tax prices of individual taxpayers requires the knowledge of, for each tax base definition and for each year, the total assessed value within a jurisdiction and the assessed value of an individual's property in that jurisdiction. In the analysis that follows I examine the effects of an alternative tax base definition on a single tax price faced by an individual.

My data are well-suited to this analysis. They are parcel level administrative data for every taxable parcel of property in the state of Minnesota from 2000 to $2009 .{ }^{12}$ I observe the estimated current market value of each parcel; these estimates are updated every year by local assessors. In addition, I observe the amount of each exemption the property receives under the Minnesota property tax system. I also observe to which taxing jurisdictions each property owes property

\footnotetext{
${ }^{12}$ These data are from the Minnesota Department of Revenue.
} 
taxes. In my analysis, I calculate the tax price faced by each parcel for taxes its owner pays to the city (i.e., municipality) it resides within.

I use these data to calculate the tax prices associated with individual parcels under five different tax base definitions. These five alternative definitions are estimated current market value, a residential assessment limit at 2\%, a residential assessment limit at 5\%, a residential assessment limit at $10 \%$, and the actual (and complicated) tax base definition in Minnesota, called Net Tax Capacity.

To start, I drop from the sample parcels in cities with population less than 5,000 and parcels in counties with any missing or inaccurate tax base data. For each remaining parcel of property in each year, I determine five different assessed values (one for each definition). Once these assessed values are determined, the calculation of tax price is straightforward. After tax prices are calculated, I include in the sample only parcels classified as residential homes that I observe in every year from 2000 to 2009. This means that I drop all properties that are not residential homes and that I drop all properties that are new construction. Because the sample is still large enough to make data analysis slow, I select a $30 \%$ random sample of the residential parcels in each city. After selecting this random sample, I have a final sample of 88, 125 parcels of property, each observed for 10 years, spanning 53 cities. All parcel-level analysis is performed on the random sample.

An important shortcoming of my data is that they allow me to calculate the tax prices of properties and not individuals over time. This is because I do not observe the identities of individual taxpayers and I do not observe property sales. Thus, if a taxpayer changes residences then I am unable to follow this individual taxpayer over time. If a taxpayer is forecasting the future costs and benefits of alternative tax base definitions under the assumption that he or she retains ownership of the current property, then these data provide an accurate description of those future costs and benefits.

I examine the tax prices of property taxes paid to the city, rather than paid to counties and school districts, for two reasons. First, in Minnesota cities are smaller geographically than most school districts and counties. ${ }^{13}$ Since cities are smaller than school districts and counties the trends in real estate market values should be more similar within a city than they are in within counties and school districts. Thus measured variation in individual tax prices should be smaller in cities than it is in school districts and counties. Because I don't expect tax prices in a city to behave differently than tax prices in a school district, I expect the analysis at the city level to have external validity for analysis at the county and school district level. Second, the analysis is most straightforward and most easily demonstrated when it is applied to only one type of taxing jurisdiction. If an individual is taxed by multiple overlapping and non-coterminous jurisdictions (e.g., city, county, or school district) then he or she will have multiple tax prices, one for each taxing jurisdiction.

\footnotetext{
${ }^{13}$ Many school districts include several cities and counties include dozens of cities.
} 
If for one individual these multiple tax prices are not very different from each other then the taxprice framework can be applied by examining the tax price in one jurisdiction only and the total consequences will be described accurately. If the tax prices do have substantive differences then an alternative tax base definition may have different consequences for, say, an individual's county tax price than for that individual's school district tax price. The appropriate way to aggregate these different tax price effects depends on the exact question being asked. In this paper, I avoid the aggregation question by focusing on one type of jurisdiction: the city.

In sum, I calculate $\frac{z_{i, t}^{j}}{R_{i, t}}$ as the difference between parcel $i$ 's tax price under the estimated current market value definition and parcel $i$ 's tax price under definition $j$. A positive $\frac{z_{i, t}^{j}}{R_{i, t}}$ implies that alternative tax base definition $j$ benefits a taxpayer owning parcel $i$ in year $t$.

I now discuss the dynamic measurements concerned with how tax base definition affects expected utility. I am unable to observe the unpredictable components of tax price necessary to estimate the $\delta_{x}^{j}$ coefficients. Thus, I base my estimates of the $\delta_{x}^{j}$ coefficients on the observed levels of tax prices which include both a predictable and unpredictable component. For each parcel, I calculate its mean tax price $\left(\bar{p}_{i, t}\right)$ and mean within-residential tax share $\left(\bar{s}_{i}\right)$ over the 10 years. I also calculate the variance of $p$ and $s$ for each property over the 10 years. Instead of reporting the variance, I report the coefficient of variation - the ratio of the standard deviation to the absolute value of the mean - for each property. Observing the effect of a tax base definition on the coefficient of variation aligns with the partial derivative intuition of equation (13).

Understanding how the tax base definition affects expected utility also requires an estimate of the covariance between unexpected permanent income and unexpected tax price. Again, I use observed values that include both a predictable and unpredictable component. Because I do not observe permanent income, I use variation in the real estimated current market value of property $\left(v_{i, t}\right)$ as a proxy. I focus on variation in $s_{i, t}$ rather than $S_{i, t}$, because this variation is at least somewhat idiosyncratic among residential taxpayers. For ease of interpretation, I estimate, the following regression for each parcel,

$$
\ln \left(v_{i, t}\right)=\zeta_{i}^{j}+\beta_{l v, l s}^{j} \cdot \ln \left(s_{i, t}^{j}\right)+\pi_{i}^{j} \quad \text { for each parcel } i \forall t \text { for each } j
$$

where $\zeta_{i}^{j}$ is a parcel-specific constant and $\pi_{i}^{j}$ is an error term. The coefficient $-\beta_{l v, l s}^{j}$ - is allowed to vary across parcels and scales the covariance by the variance. Scaling the covariance by the variance again appeals to the partial derivative intuition of equation (13). This regression uses within-parcel variation in real estimated market value and within-residential tax share to estimate the association between unexpected permanent income and within-residential tax share. If all within-parcel deviations from mean real estimated market value and mean within-residential tax share are unexpected then these $\beta^{j}$ coefficients correspond to estimates that use actual unobserv- 
able expectational errors. ${ }^{14}$

To estimate the proportion of the observed tax price variation in a city that is common rather than idiosyncratic, I estimate 265 fixed effects regressions, one for each tax base definition and each city,

$$
\ln \left(p_{i, t}^{j}\right)=a^{j}+b \cdot \ln \left(S_{i, t}^{j}\right)+\sum_{i} d_{i} \cdot 1\{\text { parcel }=i\}+e_{i, t}^{j} \quad \forall t \text { for each } j
$$

The $R^{2}$ from this regression, allowed to vary across cities, equals the proportion of the withinparcel over-time variation in tax price that is explained by within-city over-time variation in $S_{i, t}$, i.e., the within-parcel tax-price variation that is common across parcels in the city.

\subsection{Alternative Tax Base Definitions}

In this subsection, I describe how I determine assessed value under each definition. I start with an overview of the important features of the actual Minnesota definition of property tax base, called Net Tax Capacity (NTC). Although an evaluation of the actual Minnesota tax base definition is not the focus of this paper I include it in the analysis for two reasons. First, the actual Minnesota tax base definition is interesting because it is a tax base definition that is currently in practice. Second, the actual Minnesota tax base definition includes a wide array of special exemptions from market value and as a result is very complicated. My ability to use it in my framework demonstrates that my framework can be used to evaluate complicated tax base definitions. For my purposes, the three most important features of the Minnesota definition of property tax base are annual updates to estimated current market values, classification that favors residential property, and a residential property assessment limit that is phased out over this period and ends in 2006. The classification system determines tax base by multiplying each property's estimated current market value by a percentage that varies by property class. Although these percentages were not constant over the period, the classification percentage for residential property is always about half of that of the percentage for non-residential property. The relatively lower classification percentage for residential property produces substantial reductions in residential tax prices. Before it was phased out, the assessment limit prevented the assessed values of individual properties from increasing by more than a specified percentage from one year to the next. This percentage increased over the period from $8.5 \%$ to $15 \%$. The increase in assessed value was allowed to exceed this percentage if the property was sold or if the assessment limit produced too large of a difference (i.e., exemption) between assessed value and estimated market value. Because the features of the actual Minnesota

\footnotetext{
${ }^{14}$ I also estimate this equation with a linear time trend in $\ln \left(v_{i}\right)$ and in levels rather than logs and my conclusions do not change.
} 
assessment limit changed over time, this assessment limit does not provide an ideal example of tax base under an assessment limit.

For the estimated market value definition, I set assessed value equal to the annual estimates of current market value recorded as part of the NTC definition. Note that an actual switch in Minnesota from the NTC definition to a market value definition would increase the tax prices of residential property and reduce market values. Consistent with my analytical framework, I assume that tax base definition does not affect the level or time-path of estimated current market values. This assumption is appropriate because any capitalization will be driven by the differences in tax prices that I measure.

The remaining three tax base definitions are hypothetical residential assessment limits of $2 \%$, $5 \%$, and $10 \%$. Because these definitions differ only according to the percentage, I describe the tax base definition under the $2 \%$ residential assessment limit. In the year 2000, the assessed value of all property equals its current estimated market value. In all years, the assessed value of a nonresidential property equals its current estimated market value. In 2001, the assessed value of a residential property equals the minimum of its current estimated market value and (1.02) times its current estimated market value in the year 2000. In 2002, its assessed value equals the minimum of its current estimated market value and (1.02) times its assessed value in the year 2001. Generally, under an assessment limit with percentage ceiling $l>0$, assessed value in year $t+1>2000$ equals

$$
a_{t+1}=\operatorname{Min}\left[v_{t+1}, a_{t} \cdot(1+l)\right]
$$

These hypothetical assessment limits are an amalgam of actual assessment limits. Importantly, since I do not observe sales in my data it is not possible for me to simulate an assessment limit that is removed at sale. Thus, as with assessment limits in Oregon, these hypothetical assessment limits are not removed at sale. That the assessment limit applies only to residential property is similar to assessment limit in Cook County, Illinois and to the assessment limit in Florida before it was recently expanded to commercial property. As with assessment limits in California, they have no maximum exemption amount. Thus, my analysis of these assessment limits may not have external validity for the assessment limit in a specific state.

\section{Empirical Analysis}

In this section, I compare tax prices of residential parcels under the four alternative tax base definitions to tax prices of the same residential parcels under the estimated current market value definition. I find that whether a residential parcel benefits from the assessment limit and the magnitude of the benefit varies across parcels and within-parcel over time. I also find statistically and 
economically significant effects of the tax base definition on the mean, variance, and covariance of tax price. I also find that assessment limits with lower ceilings increase the share of within-city tax price variation that is common.

I begin by demonstrating that, under the estimated current market value definition, tax prices display idiosyncratic variation over time. In Figure 1, I show, for six different cities, the tax prices over time for 10 randomly selected residential parcels. Tax prices are measured per $\$ 100,000$ of total property tax revenue. Because these parcels are randomly selected from each city, their vertical distribution in one year provides an estimate of the across-parcel distribution of tax prices in that year. Following one line over time shows the path of tax price for one parcel from 2000 to 2009. For any single city, if the ten tax price lines move in parallel to each other then it indicates that the variation in tax price is common because all tax prices are changing by the same percentage. In this case, variation in $S$ - the residential tax share - is the cause of all the tax-price variation. If the tax price lines do not move in parallel then it indicates that there is idiosyncratic tax price variation. In this case, $s$ - within-residential tax share - is causing some of the tax-price variation. To understand the magnitudes of tax price variation over time, remember that holding total tax revenue constant, a percentage change in tax price is approximately equal to a percentage change in the property tax bill.

In Figure 1a, I show tax prices for 10 residential parcels in the city of Minneapolis, the largest city in Minnesota. That the ten tax price lines do not move in parallel indicates that there is idiosyncratic tax-price variation. The vertical spread of the lines indicates a wide range in tax prices at one point time. In 2009, tax prices range from a low of about one to a high of about three dollars per $\$ 100,000$ in revenue. The tax prices of some parcels of property appear relatively stable over time, but some parcels experience large variation. For example, the parcel represented by the darkest line has a tax price that starts at just under two in the year 2000 and by the year 2009 is equal to about one, implying a tax price change of approximately 50 percent. If total tax collections had remained the same over the period, then the property tax bill associated with this parcel was almost cut in half. The figures in the other five cities do not tell different stories. In sum, the tax-price variation displayed in these figures suggests that under the estimated current market value definition there is a substantial amount of idiosyncratic tax-price variation for individual parcels over time. That tax prices display idiosyncratic variation under the estimated market value definition suggests that willingness to pay may change over time and that future tax prices may be somewhat unpredictable.

In Table 1, I compare the benefits of the four alternative tax base definitions. In the top panel, I describe the benefits for all residential parcels and in the bottom two panels describe the benefits for residential parcels in the cities of Minneapolis and Bloomington. The general conclusions hold across cities. I focus on the top panel. The first column shows the mean $\frac{z_{i}}{R_{i}}$ over time for 
all taxpayers per $\$ 100,000$ of total tax revenue. For the assessment limits, the mean excludes the year 2000, in which no parcel can benefit from an assessment limit. The average benefit of the two-percent assessment limit is $\$ 0.79$, the average benefit of the-five percent assessment limit is $\$ 0.31$, and the average cost of the ten-percent assessment limit is $-\$ 0.13$. Because of its favorable classification of residential property, the NTC definition produces the largest average benefit, $\$ 1.67$. If the mean $\frac{z_{i}}{R_{i}}$ of a parcel is greater than zero then the parcel has a net benefit. Column two shows that 84 percent of parcels have a net benefit from the two-percent assessment limit. The percentage of parcels with net benefits declines as the assessment limit ceiling increases. Again, the favorable classification of residential property under NTC ensures that 99 percent of the parcels have a net benefit from the NTC definition. For the remainder of this discussion, I focus on the assessment limits.

The next set of columns in Table 1 list the percentage of residential parcels that benefit in at least a certain number of years under each alternative definition. For example, 95 percent of parcels benefit in at least one year from the two-percent assessment limit. Most interesting is that 83 percent of parcels benefit in at least half — five — of the nine years under the two-percent limit and 65 percent benefit in at least half of the years under the five-percent assessment limit. Under the ten-percent assessment limit definition, however, only 22 percent of parcels benefit in at least half of the nine years. The percentage of parcels that benefit in a given number of years declines as the assessment limit ceiling is relaxed because to benefit from the assessment limit it is necessary for a parcel to have at least one year with an appreciation rate above the ceiling and this is more widespread at a two-percent ceiling. There is important across-city variation in the percentage of parcels that benefit in a certain number of years. In Minneapolis, 58 percent of parcels benefit in all nine years from the two-percent assessment limit. In Bloomington, this percentage is 86 percent. These across-city differences are caused by across-city differences in real estate markets that affect the distribution of estimated market values and thus tax prices. I return to a discussion of across-city differences in benefits when discussing Figure 3 below.

To consider the dynamic consequences of an assessment limit, Table 1 shows the percentage of residential parcels for which the assessment limit decreases the coefficient of variation of $s$ and increases $\beta_{l v, l s}$. All three assessment limits produce benefits for the vast majority of taxpayers. The two-percent assessment limit decreases the coefficient of variation of $s$ for all parcels and increases the $\beta_{l v, l s}$ for 93 percent of parcels. A higher $\beta_{l v, l s}$ implies that - scaled by the variance of $\ln (s)$ - the $C O V(\ln (v), \ln (s))$ is higher under the assessment limit than under the estimated current market value definition. A higher covariance and lower coefficient of variation increases expected utility. ${ }^{15}$

\footnotetext{
${ }^{15}$ The NTC system benefits homeowners by reducing substantially their average tax price. It does not, however, do much to limit changes in tax prices. This explains why the coefficient of variation is not reduced under the NTC
} 
I now demonstrate that for a single parcel the benefits of an assessment limit can change over time. In Figure 2, for one randomly selected residential parcel from six different cities, I compare the tax price under the estimated market value definition to the tax price under the two-percent assessment limit definition. For example, in Figure 2a, the benefit of the assessment limit increases over time. Whether a parcel benefits also varies over time. In Figure $2 b$, the parcel benefits initially in 2001, then loses by a small margin and then begins to have large benefits beginning in 2005 . In Figure 2f, the parcel never benefits but the magnitude of its loss from the assessment limit varies over time and hits zero in 2007.

In Table 2, I present the results from regressions of five different parcel-level dependent variables on a set of four tax base definition dummies. The coefficients on these dummies are interpreted as the difference in means between the corresponding tax base definition and the current estimated market value definition. In column (1), the dependent variable is a residential parcel's mean tax price under definition $j$. This regression is motivated by equation (14) and the coefficients capture differences in expected tax prices between alternative tax base definitions. The coefficient on the two-percent assessment limit indicator implies that the average tax price under this definition is $\$ 0.29$ lower than the average tax price under the estimated market value. This average tax price is about three percent lower than it is under the estimated market value definition. The coefficient on the ten-percent assessment limit indicator implies that the average tax price under this definition is $\$ 0.23$ higher than under the estimated market value definition. Tax prices are lower under the two-percent assessment limit because the assessment limit reduces the residential tax share. Tax prices are higher under the ten-percent assessment limit because this assessment limit fails to reduce the residential tax share by a significant amount.

That this is the case is seen in the results displayed in column (2), where the dependent variable is the within-residential tax share $\left(s_{i, t}^{j}\right)$. The two-percent assessment limit increases the average $\left(s_{i, t}^{j}\right)$ by $\$ 2.51$ or about four percent higher than under the estimated market value definition. In order for $s$ to increase and $p$ to decrease it must the case, because tax price is the product of $s$ and $S$, that average $S$ - the residential tax share — is lower under the two-percent assessment limit. In sum, the estimates in column (1) suggest that, on average, the two-percent assessment limit benefits residential taxpayers (i.e., $\delta_{\mu}^{j}<0$ ) and the ten-percent assessment costs residential taxpayers (i.e., $\delta_{\mu}^{j}>0$ ).

Columns (3) and (4) display results from regressions that estimate across-definition differences in the average variance and covariance of tax price. These regressions are motivated by equations (15) and (16). In column (3), the dependent variable is the coefficient of variation in withinresidential tax share. I use the coefficient of variation rather than the variance as the dependent variable because the coefficient shows the effect of alternative tax base definitions on variance system. 
relative to the mean. Results are similar if I use the variance as the dependent variable. The coefficient on the two-percent assessment limit dummy implies that the average coefficient of variation of $s$ is lower by 0.35 under this assessment limit, implying a 100 percent reduction in the average coefficient of variation relative to the estimated market value definition. If some of the variation in $s$ is unpredictable then this reduction implies that the two-percent assessment limit increases expected utility (i.e., $\delta_{v}^{j}<0$ ) through a reduction in variance.

In column (4), the dependent variable is $\beta_{l v, l s}^{j}$, estimated for each residential property $i$ via the regression equation (20). Thus, for each individual property the dependent variable is a ratio where the numerator is the covariance between deviations from mean real home value and deviations from mean within-residential tax share and the denominator is the variance of deviations from mean within-residential tax share. I use the ratio of covariance to variance rather than covariance itself to separate the effects on covariance from the estimated effects on the variance described in column (3). Again, if these deviations from the mean are not perfectly predictable, the sign and magnitude of $\beta_{l v, l s}^{j}$ affects expected utility. That the estimated market value coefficient in column (4) is small (11.3018) and marginally statistically different from zero suggests that under the market value definition deviations of tax price and market value from their means are only weakly positively correlated. The coefficient on the two-percent assessment limit (359.5102) implies that this assessment limit produces an enormous - more than 30 times as large - increase in the $\beta_{l v, l s}^{j}$ relative to the estimated market value definition. ${ }^{16}$ The other assessment limits produce only modest increases in $\beta_{l v, l s}^{j}$.

This result deserves more explanation. Consider a simple example that demystifies the mechanics of this result. In this example, calculate the covariance of real market value and withinresidential tax share using only the first and last years of my sample, 2000 and 2009. A negative covariance is consistent with, for example, an increase in real market value and a decrease in tax share from 2000 to 2009 . Note that the difference in real market value is not affected by the tax base definition and, as in my simulation, the year 2000 within-residential tax share is not affected by the tax base definition. Thus, in this simple example only between-definition differences in the 2009 within-residential tax share cause between-definition differences in the covariance. Assuming housing value increased, if the 2009 within-residential tax share under the assessment limit is greater than the 2009 within-residential share under the market value definition then the assessment limit increases the covariance. Thus, the higher within-residential share under the assessment limit (see column (2)) explains the higher covariance and the increase in covariance demonstrates that the two-percent limit transforms the property tax into a much more effective hedge against housing value risk.

\footnotetext{
${ }^{16}$ The specification that includes a linear time trend in $\ln \left(v_{i}\right)$, which assumes that individuals can predict a linear time trend in their own real market value, produces a coefficient of 174 .
} 
Column (5) shows that tax base definition has a large effect on the share of a city's tax-price variation that is common among residential properties. In this regression the observations are at the city-definition level $(53 \times 5=265)$ rather than at the parcel level. The dependent variable is the $R^{2}$ for each city-definition of the regression of equation (21) and, as above, the independent variables are tax base definition dummies. The coefficient on the two-percent assessment limit dummy variable (0.6267) suggests that this assessment limit, relative to the market value definition, almost doubles the share of tax-price variation that is common. The coefficient on the five-percent assessment limit (0.4437) shows that this limit increases the share that is common by about ten percentage points and the coefficient on the ten-percent limit suggests that the ten-percent assessment limit does not significantly affect the common share. These results suggest that assessment limits with low ceilings reduce idiosyncratic tax-price variation.

I have demonstrated that the relative benefits of assessment limits — reduced tax prices, reduced idiosyncratic tax-price variation, increased covariance between tax price and housing value — can be shared by a vast majority of residential taxpayers. Who loses from the assessment limit? My analysis ignores the effect of alternative tax base definitions on the tax prices of non-residential properties. The assumption that non-residential property is not eligible for the hypothetical twopercent assessment limit causes the assessment limit to produce higher than otherwise tax prices for non-residential property. Although it's beyond the scope of this paper, even though the tax prices of non-residential property are higher under the assessment limit those properties may still benefit from decreased variance and increased covariance in their tax prices.

It's also interesting to consider which characteristics of residential taxpayers are associated with higher benefits. Although my administrative data do not contain information on characteristics of property owners like income or their location within a city, I am able to examine the association between the estimated market value of properties and the relative benefits of assessment limits. In Table 3, I examine to what extent across-parcel variation in mean real estimated market values explains across-parcel variation in the benefits of alternative tax base definitions. I also examine the extent to which across-parcel variation in percentage changes in real market values explains acrossparcel variation in the benefits of alternative tax base definitions. I find that the mean property value over the period 2000 to 2009 has little to no effect on either the level of benefits or the likelihood of benefiting. If home value is associated with permanent income then these results suggest that the benefits of the assessment limit are not regressive or progressive.

In contrast, and not unexpectedly, the percentage change in real estimated market value from 2000 to 2009 has statistically significant effects on both the magnitude of benefits and the likelihood of benefiting. For the two-percent assessment limit, in column (1), a one percent larger percentage increase in real estimated market value over the period is associated with a $\$ 0.03$ larger average willingness to pay. Yet even a ten percentage point larger appreciation rate is associated 
with only a $\$ 0.30$ increase in average willingness to pay, which is about a 38 percent increase over the average willingness to pay. In addition, the low $R^{2}$ from these regressions suggests that percentage changes in real estimated market values do not explain the majority of the across-parcel variation in benefits. In sum, the relative benefits of assessment limits can be shared by a vast majority of taxpayers and although the average benefits are higher for properties with greater appreciation rates the benefits are not focused exclusively on properties with high appreciation rates.

The reason that benefits are not focused exclusively on those properties with high appreciation rates is because the benefits of the assessment limit accrue to properties that have high appreciation rates relative to other properties in their jurisdiction. To see this, consider two jurisdictions that are entirely residential so that the assessment limit cannot redistribute taxes onto non-residential homes. First, I show that two properties that appreciate at the same rate can accrue different benefits from a two-percent assessment limit. If property one appreciates at eight percent and the overall appreciation rate in its jurisdiction is four percent and property two appreciates at eight percent and the overall appreciation rate in its jurisdiction is eight percent then property one benefits via a reduction in tax price and property two receives no benefit because its tax price is unchanged. Second, I show that a property that appreciates at a lower rate than another property can benefit more from a two-percent assessment limit. If property one appreciates at four percent and the overall appreciation rate in its jurisdiction is two percent and property two appreciates at eight percent and the overall appreciation rate in its jurisdiction is eight percent then property one benefits and property two does not. The reasoning is the same as above.

Figure 3 displays the distribution of the benefits of the two-percent assessment limit across different groups of homes ordered separately by real market value, real home price appreciation, and the residential tax share of a taxpayer's city. Figures for the five-percent and ten-percent assessment limits, not included in the paper, look similar but are shifted downwards to reflect lower benefits (higher costs). In sub-figures $3 \mathrm{a}$ and $3 \mathrm{~b}$, that homes in different market value deciles display similar distributions of benefits - willingness to pay and covariance - emphasizes that market value does not predict well who benefits from the two-percent assessment limit. Similarly, sub-figures $3 \mathrm{c}$ and $3 \mathrm{~d}$ demonstrate that appreciation rates do not predict well who benefits from the two-percent limit.

Returning to the issue of across-city variation in benefits, recall that the decrease in residential tax prices that creates the high willingness to pay for the two-percent assessment limit is caused, in part, by tax price increases for non-residential property. If a city had no non-residential property its residential taxpayers are unable to capture this benefit. Yet the benefits of the two-percent assessment limit are not be mechanically higher for residential taxpayers in cities with lower residential tax shares. Sub-figures $3 \mathrm{e}$ and $3 \mathrm{f}$ show that the distributions of willingness to pay and increases 
in covariance are similar across quintiles of the distribution of residential tax share. ${ }^{17}$ This is because, when residential tax share is not zero or one, the amount of tax shifting to non-residential properties is not constrained by the level residential tax share.

\section{Comparing the Tax-Price Measure to Other Measures}

In this paper, I argue that the concept of a tax price is the appropriate way to measure the consequences of alternative tax base definitions. Many other studies have focused on effective tax rates or exemption amounts as measures. Measures using effective tax rates or exemption amounts and measures using tax prices produce different answers as to the benefits of alternative tax base definitions. In this section, I illustrate the difference between these measures. To focus ideas, I will compare these measures in the context of understanding the static consequences of an assessment limit. Importantly, like the tax-price measure, neither of these two measures allows for behavioral responses. Further, like the tax-price measure, both tax rate and exemption measures are based on a conceptual experiment. Unfortunately, these conceptual experiments are often not stated clearly.

Consider the use of across-taxpayer differences in levels of effective tax rates to measure across-taxpayer differences in the direct consequences of an assessment limit. The effective tax rate equals the tax payment divided by market value. Let the assessed value of taxpayer $i$ under the estimated market value definition $(j=1)$ equal his market value, $v_{i}$, and the total assessed value in taxpayer $i$ 's jurisdiction equal total market value, $V_{i}$. Under the market value definition, there are no across-taxpayer differences in effective tax rates within a jurisdiction. Under the assessment limit definition $(j=0)$, the effective tax rate $\left(e_{i}^{0, R_{i}}\right)$ faced by taxpayer $i$ when her jurisdiction raises revenue $R_{i}$ equals

$$
e_{i}^{0, R_{i}}=\frac{p_{i}^{0} R_{i}}{v_{i}}=\frac{R_{i}}{V_{i}}\left(\frac{p_{i}^{0}}{p_{i}^{1}}\right)
$$

Under the assessment limit, the difference in effective tax rates between taxpayer $i$ and taxpayer $k$ equals

$$
e_{i}^{0, R_{i}}-e_{k}^{0, R_{k}}=\frac{R_{i}}{V_{i}}\left(\frac{p_{i}^{0}}{p_{i}^{1}}\right)-\frac{R_{k}}{V_{k}}\left(\frac{p_{k}^{0}}{p_{k}^{1}}\right)
$$

This difference in effective tax rates is often used to estimate a behavioral response to an assessment limit (e.g., its affect on mobility). There are two potential problems with this approach. First, the difference in effective tax rate does not answer a well-defined economic question. Second, the difference in effective tax rates includes the consequences not only of changes in tax prices caused by the assessment limit but also across-jurisdiction differences in revenues and total market values

\footnotetext{
${ }^{17}$ I create these quintiles by ordering taxpayers according to the residential tax share of their cities and then dividing taxpayers into five equal-sized groups.
} 
that have nothing to do with the assessment limit. ${ }^{18}$

To strip those differences out requires dividing the effective tax rate of taxpayer $i$ under the assessment limit by the effective tax rate in taxpayer $i$ 's jurisdiction, $E_{i}^{1, R_{i}}=\frac{R_{i}}{V_{i}}$, which raises revenue $R_{i}$ when tax base is defined as estimated current market value. Doing this produces

$$
\frac{e_{i}^{0, R_{i}}}{E_{i}^{1, R_{i}}}-\frac{e_{k}^{0, R_{k}}}{E_{k}^{1, R_{k}}}=\left(\frac{p_{i}^{0}}{p_{i}^{1}}\right)-\left(\frac{p_{k}^{0}}{p_{k}^{1}}\right)=-\left[\frac{z_{i}}{R_{i}}\right] \frac{1}{p_{i}^{1}}+\left[\frac{z_{k}}{R_{k}}\right] \frac{1}{p_{k}^{1}}
$$

This equation shows that the across-taxpayer difference in the proportional change in effective tax rates due to the assessment limit equals the across-taxpayer difference in the proportional change in tax prices due to the assessment limit. This difference is not the same as I obtain using my tax-price measure, $\left(\frac{z_{i}}{R_{i}}-\frac{z_{k}}{R_{k}}\right)$, because the effective tax rate measure uses proportional rather than level changes in tax prices.

Importantly, $\frac{e_{i}^{0, R_{i}}}{E_{i}^{1, R_{i}}}$, which strips out across-jurisdiction differences in revenues and total market values, answers a different economic question than my measure. My measure asks how much a taxpayer is willing to pay per dollar of revenue to avoid a switch to the estimated market value definition. As can be seen after the second equals sign in equation (25), the effective tax rate measure asks how much a taxpayer is willing to pay $\left(z_{i}\right)$ per dollar of her tax payment $\left(R_{i} p_{i}^{1}\right)$ to avoid a switch to the estimated market value definition.

Next, consider the use of across-taxpayer differences in exemption amounts to measure acrosstaxpayer differences in the direct consequences of an assessment limit. Let $x_{i}=v_{i}-a_{i}^{0}$ be the exemption amount for taxpayer $i$, where $a_{i}^{0}$ is assessed value for taxpayer $i$ under the assessment limit, $A_{i}^{0}$ is total assessed value under the assessment limit and total exemptions equal $X_{i}=V_{i}-A_{i}^{0}$. I can express the exemption amount for taxpayer $i$ as a function of tax prices

$$
x_{i}=v_{i}-a_{i}^{0}=\left[p_{i}^{1}-p_{i}^{0}\right] A_{i}^{0}+p_{i}^{1} X_{i}
$$

Because it does not include across-jurisdiction differences in tax rates or revenues, equation (26) isolates a direct effect of the assessment limit. It is not clear, however, if measuring across-taxpayer differences in $x_{i}$ answers a well-defined economic question. Noting that $\left[p_{i}^{1}-p_{i}^{0}\right]=\frac{z_{i}}{R_{i}}$, the acrosstaxpayer difference in exemption amounts equals

$$
x_{i}-x_{k}=\left[\frac{z_{i}}{R_{i}}-\frac{z_{k}}{R_{k}}\right]+\left(\left[\frac{z_{i}}{R_{i}}+p_{i}^{0}\right] \frac{A_{i}^{0}}{X_{i}}-\left[\frac{z_{k}}{R_{k}}+p_{i}^{0}\right] \frac{A_{k}^{0}}{X_{k}}\right)
$$

\footnotetext{
${ }^{18}$ To see how this measure, equation (24), can create a false impression of benefits from an assessment limit, consider an assessment limit that leaves the tax prices of taxpayers $i$ and $k$ unchanged so that the tax price ratios both equal one and assume that $V_{i}=V_{k}$. If $R_{i}>R_{k}$ then equation (24) says that taxpayer $i$ benefits from the assessment limit. Yet taxpayer $i$ has no willingness to pay to avoid a switch from the assessment limit to the market value definition.
} 
This difference in exemption amounts is sometimes used to estimate a behavioral response to an assessment limit. The difference in exemptions amounts includes my measure of differences in willingness to pay per dollar of revenue (the first term in brackets) and adds an extra term (the second term in parentheses), which is difficult to interpret in economically meaningful ways.

\section{Conclusion}

In a property tax system, the choice of the definition of the property tax base determines the current distribution of the property tax burden and expectations about the future distribution of the property tax burden. In this paper, I present a framework for measuring the direct consequences of alternative tax base definitions for the distribution of the current and future property tax burden. The consequences are direct because I measure them in the absence of behavioral responses. This framework is general; it can be used to understand the consequences of a wide variety of alternative tax base definitions. Unlike previous measures, this new framework is based on tax prices and is thus able to separate the effect of alternative tax base definitions from the effects of across-jurisdiction differences in tax revenues and tax rates. This new measure is based on a welldefined economic question and it is the first to consider the implications of the choice of tax base definitions for the distribution of future property tax burdens under uncertainty. I show that understanding the consequences of alternative tax base definitions under uncertainty requires a focus on the mean, variance, and covariance of future tax prices as well as the share of tax-price variation that is common rather than idiosyncratic.

Using unique administrative data, I establish that under current market value assessment there is a substantial amount of idiosyncratic variation in the tax prices of individual taxpayers. This idiosyncratic tax-price variation produces large changes in the tax bills of individual taxpayers even when the total tax revenue within the jurisdiction is held constant. I argue that some of this idiosyncratic tax-price variation is not predictable and thus there exists idiosyncratic tax-price risk. Importantly, the empirical evidence demonstrates that variation in individuals' tax prices is not strongly correlated with variation in their housing values. This suggests that if tax base is defined as current market value then unpredictable changes in housing wealth do not offer an effective hedge against unpredictable idiosyncratic tax price changes. This is an important result.

In this paper, I consider the implications of idiosyncratic tax-price variation on the advantages and disadvantages of a hypothetical assessment limit. Previous research has focused on an important disadvantage of an assessment limit, that it produces non-uniform assessments. That is, because under an assessment limit taxpayers are taxed at different effective tax rates, an assessment limit produces a less equitable distribution — in terms of housing value — of the statutory property tax burden than does current market value assessment. This paper, however, is the first 
to show that an assessment limit can also produce several important advantages. I find that the relative benefits of this assessment limit - a reduction in mean tax price, a reduction in tax-price variance, and increased covariance between tax price and housing value - can be shared by a vast majority of taxpayers and these benefits do not appear to be skewed towards the wealthy. I also demonstrate that, although the average benefits of assessment limits are higher for properties with greater appreciation rates, the benefits are not focused exclusively on such properties. That the benefits of an assessment limits are conveyed to a majority of taxpayers of homeowners suggests that, notwithstanding equity concerns, that an assessment limit can increase social welfare. In sum, that many states choose to depart from a current market value definition of the tax base suggests an effort to reduce idiosyncratic tax-price risk.

Of course, an assessment limit represents only one example of a departure from the current market value definition of property tax base. Other examples of departures from the current market value definition include fixed assessed values, biennial reassessments, and homestead exemptions. ${ }^{19}$ Each of these departures can have important effects on current tax prices and expectations about future tax prices and tax burdens. Future research should examine the consequences of these alternative definitions. For example, in evaluating the choice between an annual and triennial reassessment cycle, evidence on the amount of idiosyncratic tax-price variation is essential. In non-reassessment years there is less assessment uniformity and tax prices have no idiosyncratic variation because they are not changing. In reassessment years, there is more uniformity and tax prices exhibit idiosyncratic variation. This paper presents evidence that taxpayers may prefer the triennial system because it has relatively fewer years of tax-price uncertainty — it is not necessary that the relative magnitude of tax-price uncertainty is higher under triennial reassessment - even though it has relatively less equity in statutory tax payments.

Finally, I want to emphasize again that my new tax-price measure can be an appropriate independent variable in studies that estimate behavioral responses to alternative tax base definitions. For example, many papers estimate the difference in household mobility between a tax system that defines tax base under an assessment limit and a counterfactual system that defines tax base as current market value. If the tax-price measure is the independent variable then the effect of the assessment limit on mobility is identified by between-taxpayer variation in the effect of the assessment limit on revenue-neutral tax payments. That is, the independent variable captures only between-definition variation in tax payments caused directly by the assessment limit. If the level of the effective tax rate is the independent variable, see equation (24), then the effect on mobility is identified by the variation caused only by the assessment limit and across-jurisdiction differences in the level of tax revenues selected under the assessment limit. Research that uses effective tax rates to estimate behavioral responses must either control for these across-jurisdiction revenue dif-

\footnotetext{
${ }^{19}$ See Bogart and Bradford (1990) for a thoughtful discussion of the advantages of fixed assessed values.
} 
ferences or explain why using this variation in revenues does not result in measurement error or omitted variable bias. Future work should evaluate the implications, in theory and in practice, of the choice of the independent variable when estimating behavioral responses to alternative definitions of the property tax base. 


\section{References}

Alm, J., R. D. Bushman, And D. L. Sjoquist (2011): "Rethinking local government reliance on the property tax," Regional Science and Urban Economics, 41(4), 320-331.

Anderson, N. B. (2006a): "Beggar Thy Neighbor? Property Taxation of Vacation Homes," National Tax Journal, 59(4), 757-780.

(2006b): “Property Tax Limitations: An Interpretative Review," National Tax Journal, 59(3), 685-694.

(2011): "No relief: Tax prices and property tax burdens," Regional Science and Urban Economics, 41(6), 537-549.

Anderson, N. B., And A. D. PAPE (2011): “A Model of Constitutional Constraints on Benevolent Government and a Reassessment of the 1970s Property Tax Revolt,” working paper.

Auerbach, A. J., And J. R. Hines (2002): “Taxation and Economic Efficiency," in Handbook of Public Economics, Volume 3, ed. by A. Auerbach, and M. Feldstein, pp. 1347-1421. Chicago: University of Chicago Press.

Bogart, W. T., ANd D. F. BrAdFORD (1990): “Incidence and Allocation Effects of the Property Tax and a Proposal for Reform," Research in Urban Economics, 8, 59-82.

Bradley, S. (2011): "Capitalizing on Capped Taxable Values: How Michigan Homebuyers are Paying for Assessment Limits," working paper.

Cheung, R., And C. Cunningham (2011): "Who supports portable assessment caps: The role of lock-in, mobility, and tax share," Regional Science and Urban Economics, 41, 173-186.

Dye, R. F., T. J. MCGuire, And D. F. Merriman (2001): “The Impact of Property Taxes and Property Tax Classification on Business Activity in the Chicago Metropolitan Area," Journal of Regional Science, 41(4), 757-777.

Dye, R. F., And D. P. MCMillen (2007): “The Algebra of Tax Burden Shifts from Assessment Limitations," Lincoln Institute of Land Policy Working Paper.

FERreirA, F. (2010): "You can take it with you: Proposition 13 tax benefits, residential mobility, and willingness to pay for housing amenities," Journal of Public Economics, 94, 661-673.

IHLANFELDT, K. R. (2011): "Do Caps on Increases in Assessed Values Create a Lock-In Effect? Evidence From Florida's Amendment One," National Tax Journal, 64(1), 7-26. 
Lutz, B., R. Molloy, And H. Shan (2011): "The housing crisis and state and local government tax revenue: Five channels," Regional Science and Urban Economics, 41(4), 306-319.

O’Sullivan, A., T. A. Sexton, And S. M. Sheffrin (1995): Property Taxes and Tax Revolts: The Legacy of Proposition 13. Cambridge University Press.

Rockoff, J. E. (2010): “Local Response to Fiscal Incentives in Heterogeneous Communities," Journal of Urban Economics, 68(2), 138-147.

Skidmore, M., C. L. Ballard, and T. R. Hodge (2010): "Property Value Assessment Growth Limits and Redistribution of Property Tax Payments: Evidence from Michigan," National Tax Journal, 60(3), 509-538.

VARIAN, H. R. (1980): “Redistributive Taxation As Social Insurance," Journal of Public Economics, 14(1), 49-68. 


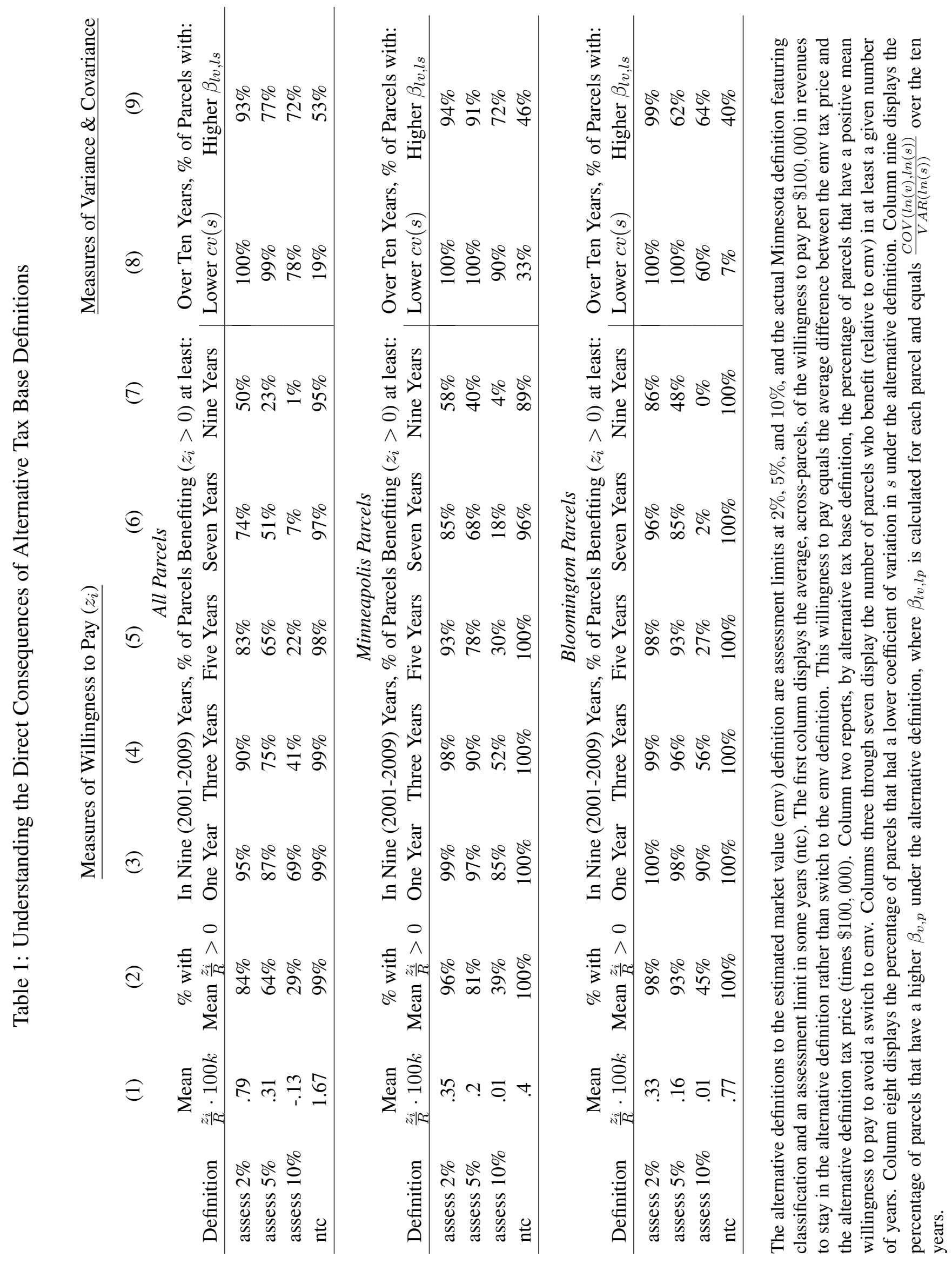


Table 2: Estimating Direct Consequences of Alternative Tax Base Definitions

\begin{tabular}{|c|c|c|c|c|c|}
\hline \multirow[b]{4}{*}{ Definition $[0,1]$} & \multicolumn{2}{|c|}{ Mean Tax Prices per $\$ 100,000$} & \multicolumn{3}{|c|}{ Measures of Var and Cov of Tax Prices } \\
\hline & \multirow{3}{*}{$\begin{array}{c}\text { (1) } \\
\text { within-city } \\
\bar{p}_{i}^{j}\end{array}$} & \multirow{3}{*}{$\begin{array}{c}\text { (2) } \\
\text { within-residential } \\
\bar{s}_{i}^{j}\end{array}$} & (3) & (4) & \multirow{3}{*}{$\begin{array}{c}(5) \\
\text { within-city } \\
\text { Percent Variation } \\
\text { Common to Homes } \\
{[0,1]}\end{array}$} \\
\hline & & & \multicolumn{2}{|c|}{ within-residential } & \\
\hline & & & $\begin{array}{l}\text { Coefficient of } \\
\text { Variation } \\
\quad c v\left(s_{i}^{j}\right)\end{array}$ & $\begin{array}{c}\text { Covariance with } \\
\text { Market Value } \\
\hat{\beta}_{l v, l s}^{j}\end{array}$ & \\
\hline assess $2 \%$ & $\begin{array}{l}-0.2914^{*} \\
(0.1325)\end{array}$ & $\begin{array}{c}2.5149^{* * *} \\
(0.6932)\end{array}$ & $\begin{array}{c}-0.3525^{* * *} \\
(0.0502)\end{array}$ & $\begin{array}{c}359.5102^{* * *} \\
(69.7780)\end{array}$ & $\begin{array}{c}0.6267^{* * *} \\
(0.0329)\end{array}$ \\
\hline assess $5 \%$ & $\begin{array}{c}-0.1085^{+} \\
(0.0596)\end{array}$ & $\begin{array}{c}0.9609^{* *} \\
(0.3025)\end{array}$ & $\begin{array}{c}-0.2858^{* * *} \\
(0.0480)\end{array}$ & $\begin{array}{l}9.8361^{*} \\
(4.1145)\end{array}$ & $\begin{array}{c}0.4437^{* * *} \\
(0.0431)\end{array}$ \\
\hline assess $10 \%$ & $\begin{array}{c}0.2334^{* * *} \\
(0.0565)\end{array}$ & $\begin{array}{l}0.6608^{* *} \\
(0.2150)\end{array}$ & $\begin{array}{c}-0.0865^{* * *} \\
(0.0196)\end{array}$ & $\begin{array}{c}1.0572^{* * *} \\
(0.0652)\end{array}$ & $\begin{array}{c}0.0177 \\
(0.0451)\end{array}$ \\
\hline ntc & $\begin{array}{c}-1.5159^{* * *} \\
(0.1621)\end{array}$ & $\begin{array}{l}-0.0546 \\
(0.1473)\end{array}$ & $\begin{array}{c}0.1276^{* * *} \\
(0.0099)\end{array}$ & $\begin{array}{l}0.1069^{*} \\
(0.0481)\end{array}$ & $\begin{array}{c}0.0478 \\
(0.0424)\end{array}$ \\
\hline emv & $\begin{array}{c}10.1795^{* * *} \\
(1.1569)\end{array}$ & $\begin{array}{l}59.1021^{* * *} \\
(6.2806)\end{array}$ & $\begin{array}{c}0.3643^{* * *} \\
(0.0513)\end{array}$ & $\begin{array}{c}11.3018^{+} \\
(6.5295)\end{array}$ & $\begin{array}{c}0.3403^{* * *} \\
(0.0318)\end{array}$ \\
\hline$N$ & 440625 & 440625 & 440625 & 440625 & 265 \\
\hline$R^{2}$ & 0.041 & 0.040 & 0.147 & 0.347 & 0.632 \\
\hline
\end{tabular}

Standard errors (clustered at the city) in parentheses

${ }^{+} p<0.10,{ }^{*} p<0.05,{ }^{* *} p<0.01,{ }^{* * *} p<0.001$

The sample is 88,125 parcels each with one observation for each of the five alternative tax base definition for a total of 440, 625 observations. The five definitions are estimated market value (emv) [the base definition], an assessment limit at 2\%, an assessment limit at 5\%, an assessment limit at 10\%, and the actual definition in Minnesota (ntc). The five outcome variables are: (1) a parcel's average tax price under a definition; (2) a parcel's average within-residential tax share $s_{i}$ under a definition; (3) a parcel's coefficient of variation for the within-residential share $\left(s_{i}\right)$ under a definition; (4) for each parcel, the estimated coefficient from the regression $\ln \left(v_{i, t}\right)=a+\beta_{l v, l p} \ln \left(p_{i, t}\right)+u_{i, t}$; (5) the $R^{2}$, for each city, from a parcel-fixed effects regression $\ln \left(v_{i, t}\right)$ on residential tax share for the years 2000 to 2009 . The column (5) regression is equivalent to a parcel-fixed effects regression $\ln \left(v_{i, t}\right)$ on year dummies for the years 2000 to 2009. The sample size is smaller in column (5) because the outcome variable is based on the entire period and not on each year. Control variables differ across columns. Column (5) have no additional control variables. Columns (1) and (2) control for $\operatorname{var}\left(s_{i}\right)$ and $\operatorname{cov}\left(v_{i}, s_{i}\right)$. Column (3) controls for $\operatorname{cov}\left(v_{i}, s_{i}\right)$ and column (4) controls for the mean of $s_{i}$. Results are almost identical without controls. 
Table 3: The Relationship Between Property Values and Benefits of Departures from Estimated Market Value

\begin{tabular}{|c|c|c|c|c|c|c|c|c|}
\hline \multirow[b]{4}{*}{ market value } & \multicolumn{2}{|c|}{ Willingness to Pay } & \multicolumn{2}{|c|}{ Covariance \& Variance } & \multicolumn{2}{|c|}{ Willingness to Pay } & \multicolumn{2}{|c|}{ Covariance \& Variance } \\
\hline & (1) & (2) & (3) & (4) & (5) & (6) & (7) & (8) \\
\hline & \multicolumn{4}{|c|}{ Assessment Limit $2 \%$} & \multicolumn{4}{|c|}{ Assessment Limit $5 \%$} \\
\hline & $\underset{\frac{z}{R}}{\operatorname{Mean}}$ & $\begin{array}{l}z_{i, t}>0 \\
\text { Always }\end{array}$ & $\Delta \hat{\beta}_{l v, l s}$ & $\Delta c v\left(s_{i}\right)$ & $\underset{\frac{\bar{z}}{R}}{\operatorname{Mean}}$ & $\begin{array}{l}z_{i, t}>0 \\
\text { Always }\end{array}$ & $\Delta \hat{\beta}_{l v, l s}$ & $\Delta c v\left(s_{i}\right)$ \\
\hline$\% \Delta v_{i, 00-09}$ & $\begin{array}{l}0.0314^{* *} \\
(0.0040)\end{array}$ & $\begin{array}{l}0.0035^{* *} \\
(0.0006)\end{array}$ & $\begin{array}{l}3.1111^{* *} \\
(0.5741)\end{array}$ & $\begin{array}{c}-0.0039^{* *} \\
(0.0006)\end{array}$ & $\begin{array}{c}0.0309^{* *} \\
(0.0039)\end{array}$ & $\begin{array}{c}0.0041^{* *} \\
(0.0007)\end{array}$ & $\begin{array}{c}0.2065^{*} \\
(0.0916)\end{array}$ & $\begin{array}{c}-0.0045^{* *} \\
(0.0006)\end{array}$ \\
\hline $\bar{v}_{i}(\$ 100 k)$ & $\begin{array}{l}0.1905^{+} \\
(0.1008)\end{array}$ & $\begin{array}{r}-0.0198^{+} \\
(0.0102)\end{array}$ & $\begin{array}{c}-7.0884 \\
(12.4507)\end{array}$ & $\begin{array}{l}-0.0819 \\
(0.0514)\end{array}$ & $\begin{array}{l}0.1465^{+} \\
(0.0800)\end{array}$ & $\begin{array}{c}0.0007 \\
(0.0074)\end{array}$ & $\begin{array}{c}0.9934 \\
(0.6644)\end{array}$ & $\begin{array}{l}-0.0776 \\
(0.0482)\end{array}$ \\
\hline$\overline{R^{2}}$ & 0.291 & 0.055 & 0.055 & 0.165 & 0.309 & 0.111 & 0.084 & 0.202 \\
\hline
\end{tabular}

\begin{tabular}{|c|c|c|c|c|c|c|c|c|}
\hline \multirow[b]{2}{*}{ market value } & \multicolumn{4}{|c|}{ Assessment Limit $10 \%$} & \multicolumn{4}{|c|}{ Actual MN System (ntc) } \\
\hline & $\begin{array}{c}\text { Mean } \\
\frac{z}{R}\end{array}$ & $\begin{array}{l}z_{i, t}>0 \\
\text { Always }\end{array}$ & $\Delta \hat{\beta}_{l v, l s}$ & $\Delta c v\left(s_{i}\right)$ & $\underset{\frac{\bar{z}}{R}}{\text { Mean }}$ & $\begin{array}{l}z_{i, t}>0 \\
\text { Always }\end{array}$ & $\Delta \hat{\beta}_{l v, l s}$ & $\Delta c v\left(s_{i}\right)$ \\
\hline$\% \Delta v_{i, 00-09}$ & $\begin{array}{c}0.0249^{* *} \\
(0.0035)\end{array}$ & $\begin{array}{c}0.0014^{* *} \\
(0.0001)\end{array}$ & $\begin{array}{c}0.0002 \\
(0.0010)\end{array}$ & $\begin{array}{c}-0.0027^{* *} \\
(0.0004)\end{array}$ & $\begin{array}{c}0.0077^{*} \\
(0.0035)\end{array}$ & $\begin{array}{c}-0.0003^{+} \\
(0.0001)\end{array}$ & $\begin{array}{c}-0.0030^{* *} \\
(0.0006)\end{array}$ & $\begin{array}{l}0.0006^{* *} \\
(0.0002)\end{array}$ \\
\hline $\bar{v}_{i}(\$ 100 k)$ & $\begin{array}{c}0.0811 \\
(0.0489)\end{array}$ & $\begin{array}{c}0.0037^{*} \\
(0.0014)\end{array}$ & $\begin{array}{l}-0.0223 \\
(0.0280)\end{array}$ & $\begin{array}{l}-0.0270 \\
(0.0171)\end{array}$ & $\begin{array}{c}0.0608 \\
(0.1021)\end{array}$ & $\begin{array}{c}-0.0270^{* *} \\
(0.0073)\end{array}$ & $\begin{array}{c}-0.1114^{* *} \\
(0.0309)\end{array}$ & $\begin{array}{c}0.0100 \\
(0.0111)\end{array}$ \\
\hline$R^{2}$ & 0.294 & 0.233 & 0.000 & 0.172 & 0.014 & 0.052 & 0.015 & 0.009 \\
\hline
\end{tabular}

$N=88,125$. Standard errors (clustered at city) in parentheses

${ }^{+} p<0.10,{ }^{*} p<0.05,{ }^{* *} p<0.01$

Table presents regression results, under each alternative definition, that evaluate the extent to which across-parcel variation in the ten-year appreciation rate $[1=1 \%]$ in real estimated market value, $\% \Delta v_{i, 00-09}$, and the mean real property value (in hundreds of thousands of 2009 dollars), $\bar{v}_{i}(\$ 100 k)$, is associated with across-parcel variation in the benefits of departures from the estimated market value definition. The four outcome variables, repeated for each alternative definition, are: (1) the average, over time, $\frac{z}{R}$ for a parcel, (2) an indicator variable equal to one if the parcel has a positive willingness to pay $\left(z_{i}>0\right)$ in all periods, (3) the difference between the estimated coefficient in the regression $\ln \left(v_{i, t}\right)=a+\beta_{l v, l s} \ln \left(s_{i, t}\right)$ for the alternative (alt) definition and the emv system, so that $\Delta \hat{\beta}_{l v, l s}=$ $\hat{\beta}^{\text {alt }}-\hat{\beta}^{e m v}$, and (4) the difference between the coefficient of variation of $s_{i}$ in the alternative definition and the coefficient of variation of $s_{i}$ in the emv definition so that $\Delta c v\left(s_{i}\right)=c v\left(s_{i}^{a l t}\right)-c v\left(s_{i}^{e m v}\right)$. 

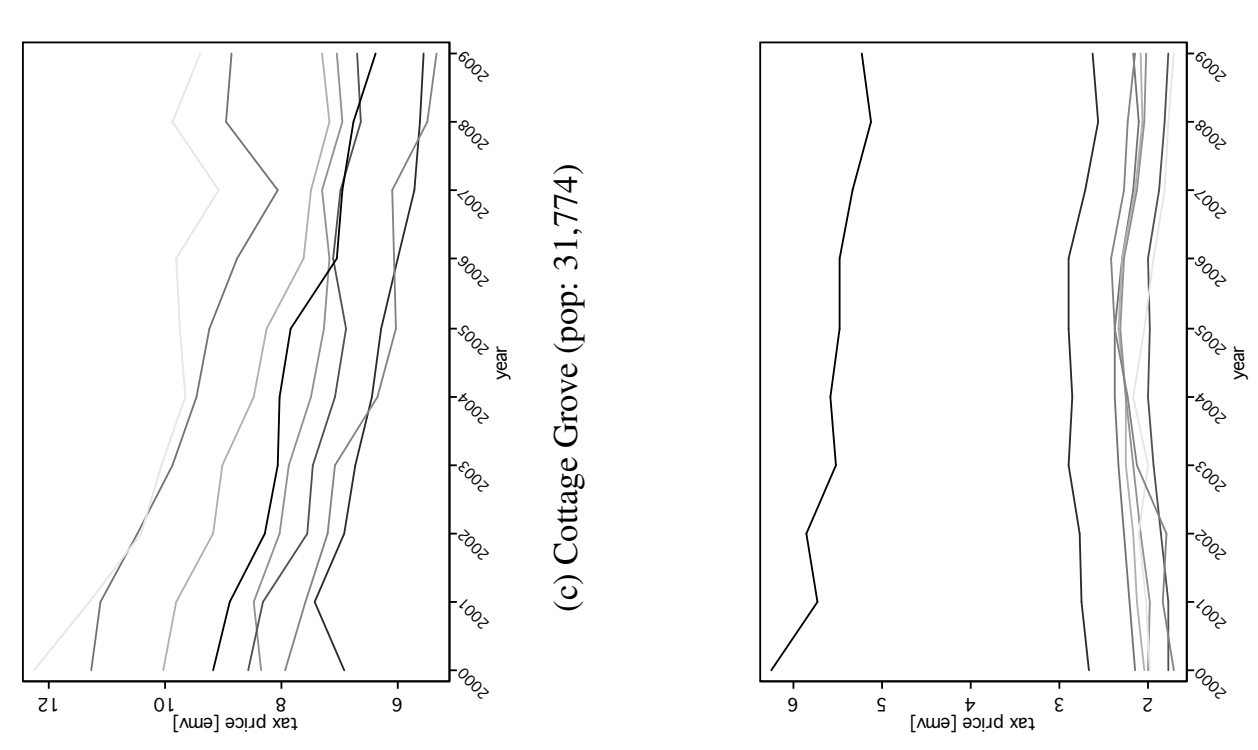

뭄요
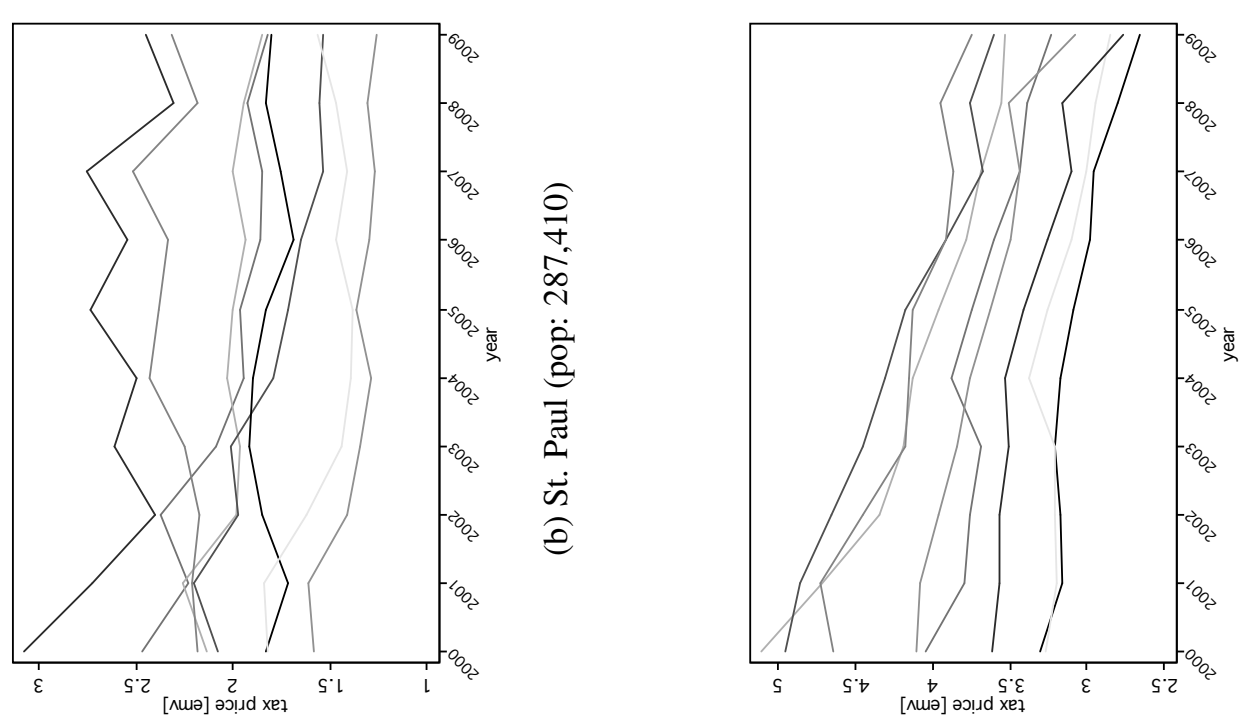

䨌

ชิ 응

i d

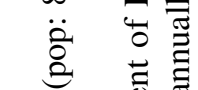

ธี อี

동

วั๊

은

$\Theta$

宅

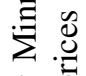

:

造

ส $\check{\sigma}$

बे ठ્仓

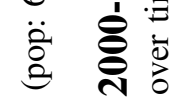

ह

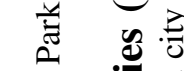

(

永

串

(1)

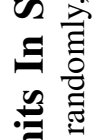
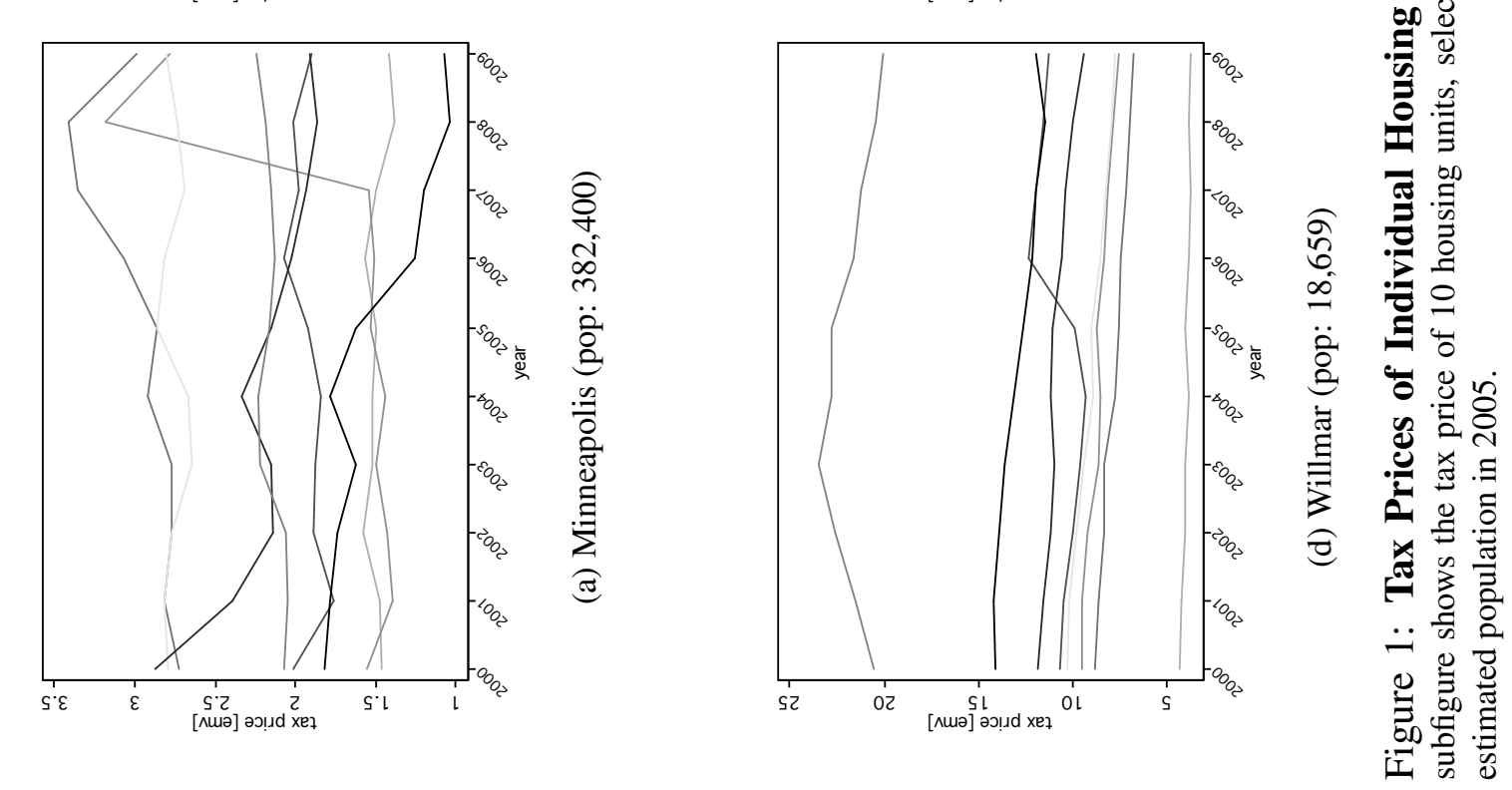

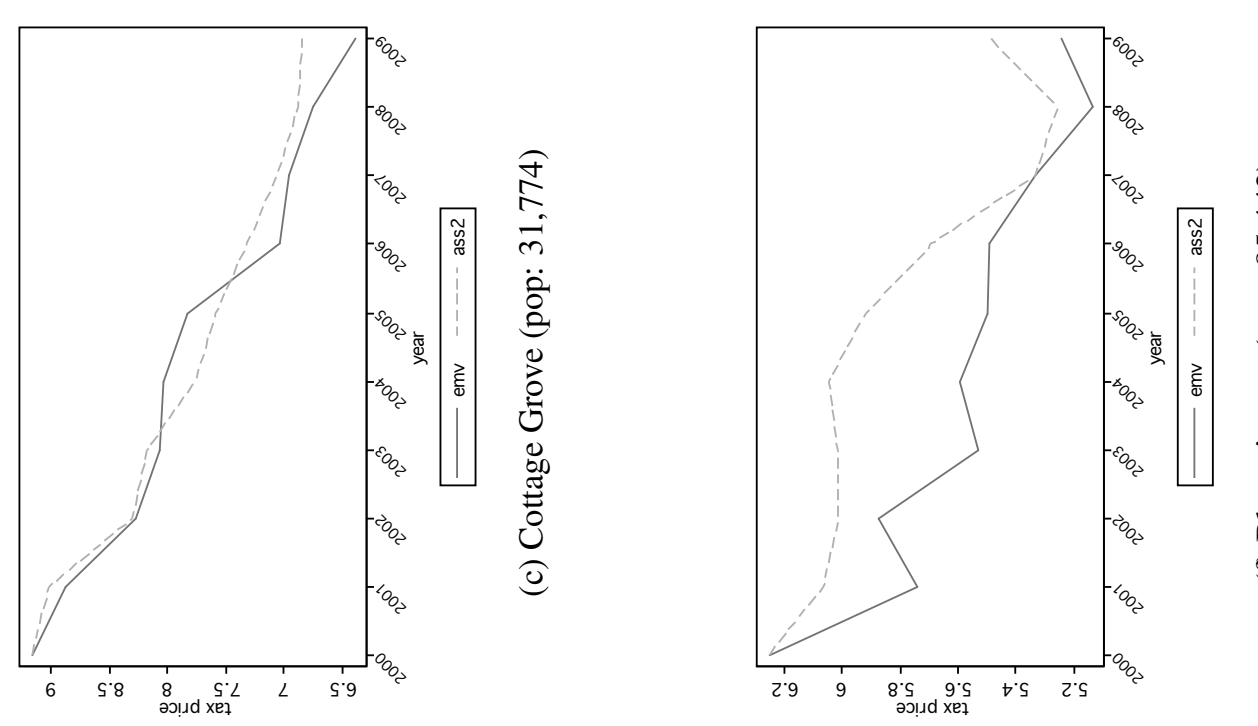

륭 $\dot{0} \cdot \bar{\Xi}$

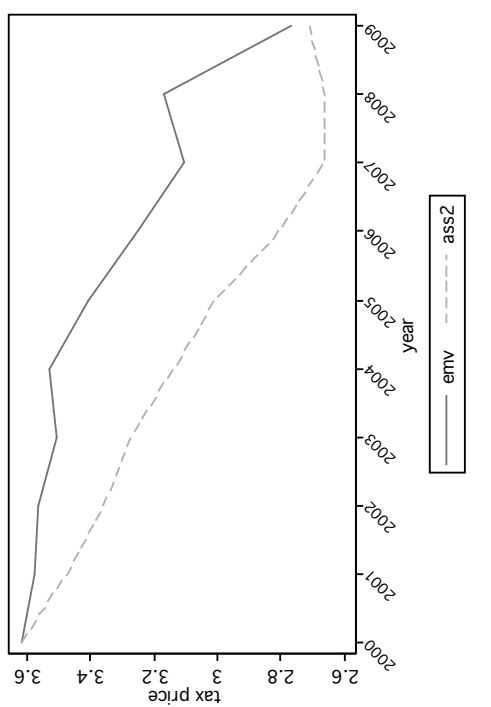

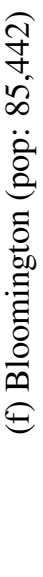

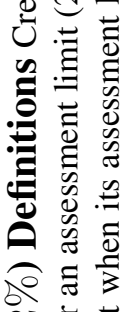

ํㅝ

言

四

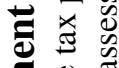

吾志

ฟ

$\sum \cong$

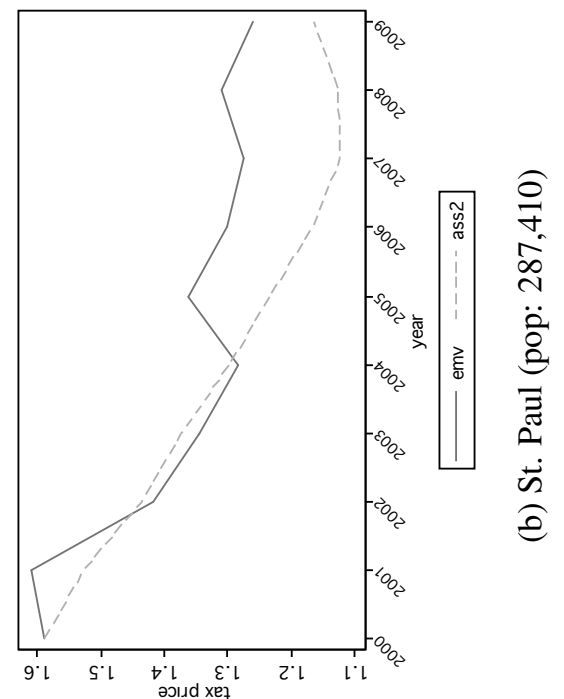

호

قิ

光芯施

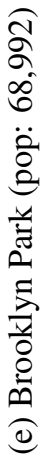

氙

ㄱ.

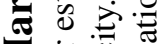

$\sum \frac{\vec{v}}{0} \bar{\Xi}$

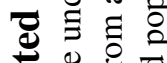

过

至令

되 웡 웡

ఫัँ

름

可

巳

记昰
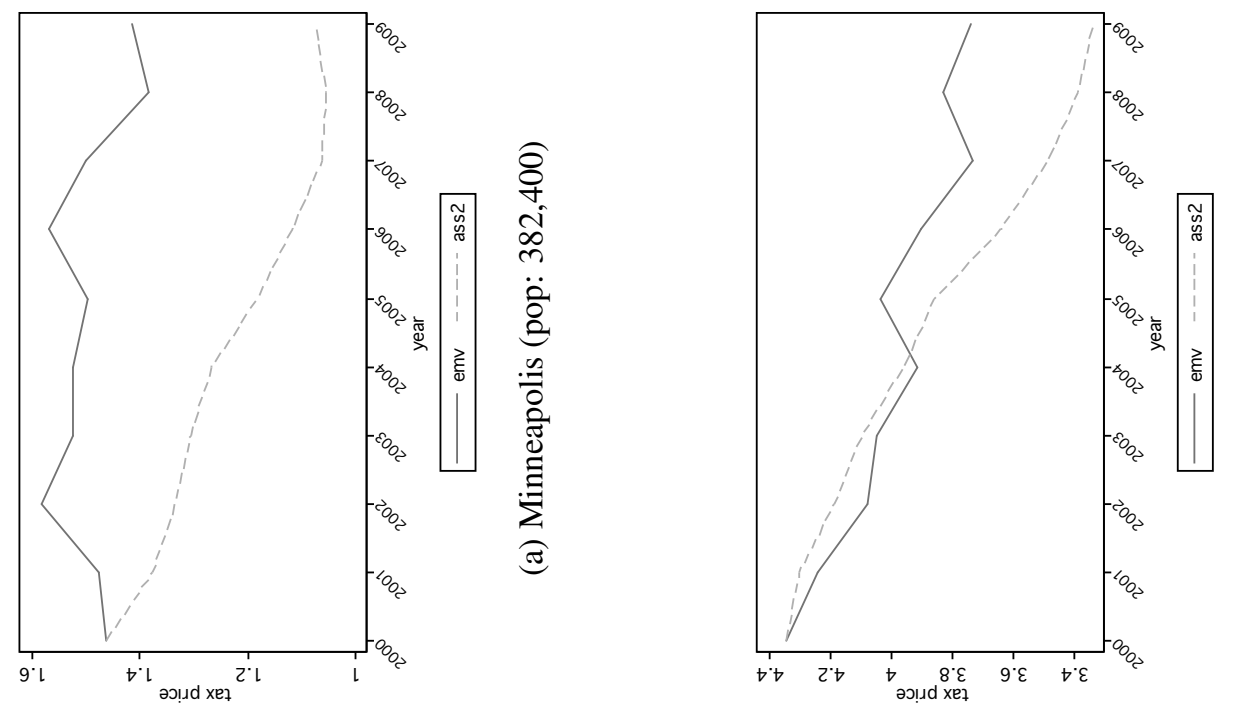

है

के

额

버웛

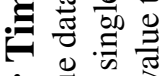

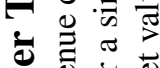

ठ己

क्ष

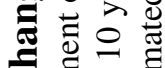

氙宫

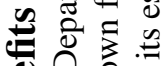

焉

त

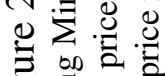

可需蔍 

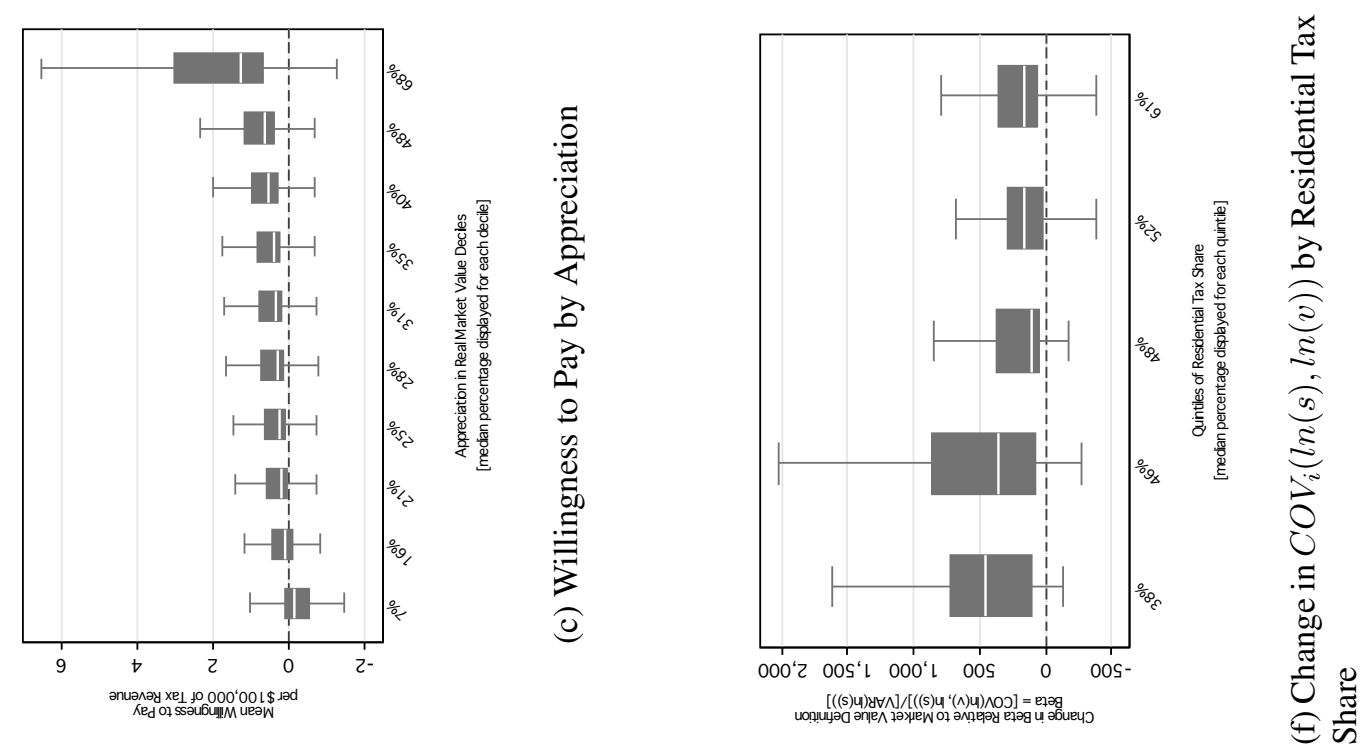

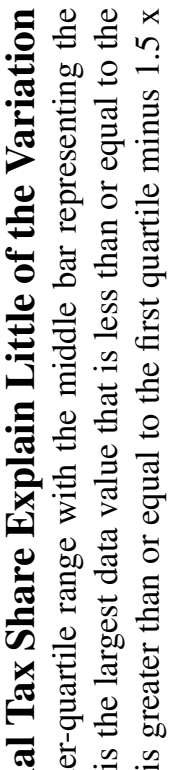
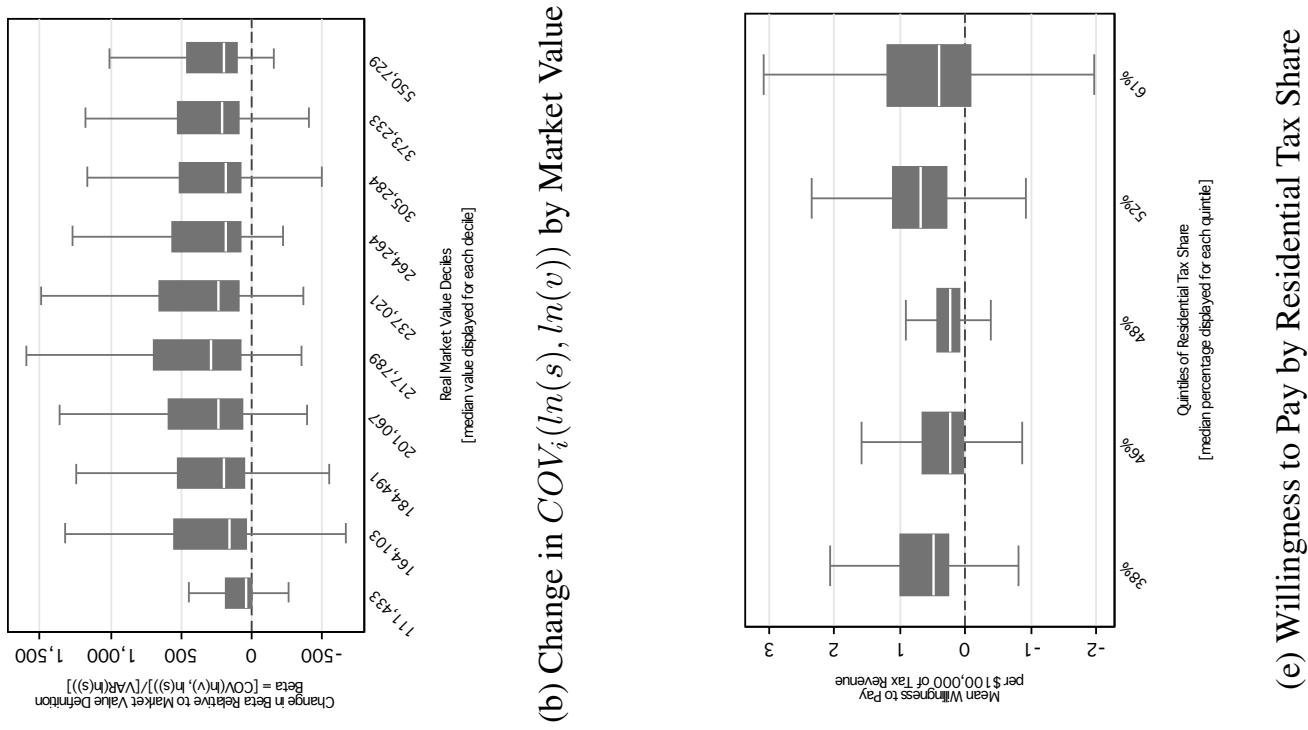

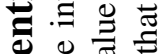

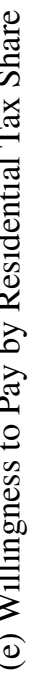
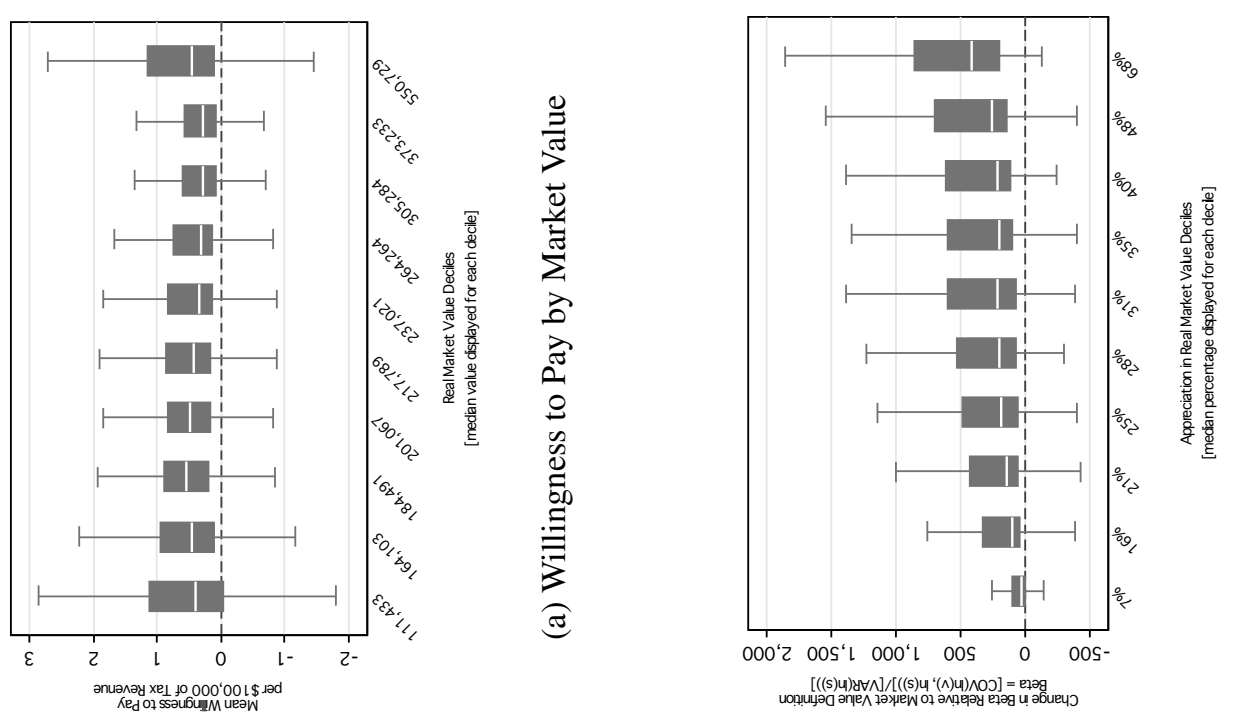

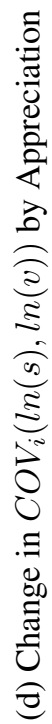

证

幽

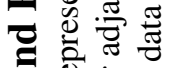

힌

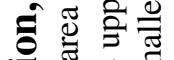

o

音

的兽.

र等焉

ये

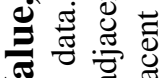

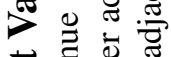

过

출 음

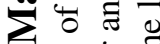

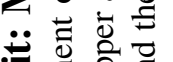

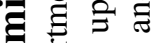

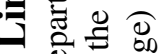

Е ๑ 을

후

जे

会蓄

$\sum_{000}$

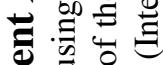

过记

웜

늘

里

桄

Ð छ

: 